The Dredging Research Program (DRP) is a seven-year program of the U.S. Army Corps of Engineers. DRP research is managed in these five technical areas:

Area 1 - Analysis of Dredged Material Placed in Open Water

Area 2 - Material Properties Related to Navigation and Dredging

Area 3 - Dredge Plant Equipment and Systems Processes

Area 4 - Vessel Positioning, Survey Controls, and Dredge Monitoring Systems

Area 5 - Management of Dredging Projects

The contents of this report are not to be used for advertising, publication, or promotional purposes. Citation of trade names does not constitute an official endorsement or approval of the use of such commercial products. 


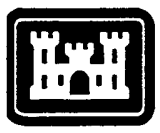

US Army Corps

of Engineers

Waterways Experiment

Station

\section{Dredging Research Program Report Summary}

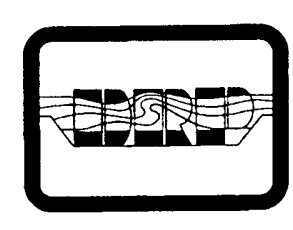

Vessel Positioning, Survey Controls, and Dredge Monitoring Systems; Summary Report for Technical Area 4 (TR DRP-95-9)

ISSUE: The navigation mission of the Corps of Engineers entails maintenance dredging of about $40,000 \mathrm{~km}$ of navigable channels at an annual cost of about $\$ 400$ million. Deficiencies in the dredging program have been documented by the Cops field operating Division and District offices. Implementation of Dredging Research Program (DRP) to meet demands of changing conditions related to dredging activities, and the generation of significant technology that will be adopted by all dredging interests, are means to reduce the cost of dredging the Nation's waterways and harbors and save taxpayer dollars.

RESEARCH: Investigations conducted under DRP Technical Report Area 4, "Vessel Positioning, Survey Controls, and Dredge Monitoring Systems," addressed the need for reporting offshore onsite water levels and an enhanced vessel-heave system for dredging purposes, developed real-time, on-the-fly GPS navigation for surveying and dredging, evaluated dredge production meters, and developed the operational aspects of a silent inspector for monitoring contract hopper dredges.

SUMMARY: The WES-developed automated real-time tidal elevation system (ARTTES) was enhanced to prevent access denial when threshold conditions for surveying may not be severe enough to preclude dredging operations. Differential GPS technology was developed so that only one fixed reference station of known coordinates ( $\mathrm{x}, \mathrm{y}, \mathrm{z}$ position) located every $20 \mathrm{~km}$ would provide the user with $2-\mathrm{cm}$ (1-in.) accuracy (far better than the specification goal of 1-dm (4-in.) accuracy) for dredgingquantity determination for contract estimation and final payment computations. Production meters were evaluated in both the laboratory and field to determine their reliability of operation under different dredged material conditions. The silent inspector produces a factual record of a contract hopper dredge's activities that is sufficient for dredging inspectors to accurately assess contract performance even in the absence of a full-time onboard inspector.

AVAILABILITY OF REPORT: The report is available through the Interlibrary Loan Service from the U.S. Army Engineer Waterways Experiment Station (WES) Library, telephone (601) 634- 2355. National Technical Information Service (NTIS) report numbers may be requested from WES Librarians. To purchase a copy of the report, call NTIS at (703) 487-4780.

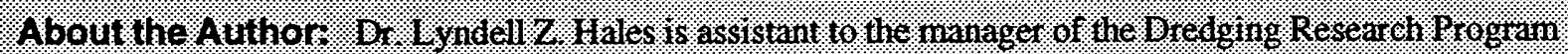

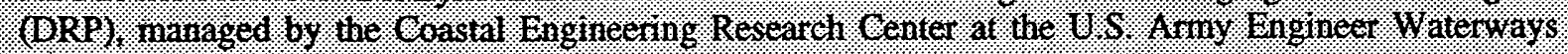
Experinent Station.

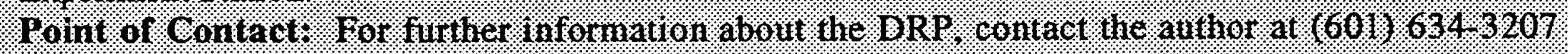

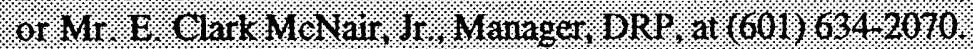




\title{
Vessel Positioning, Survey Controls, and Dredge Monitoring Systems; Summary Report for Technical Area 4
}

\author{
compiled by Lyndell Z. Hales \\ U.S. Army Corps of Engineers \\ Waterways Experiment Station \\ 3909 Halls Ferry Road \\ Vicksburg, MS 39180-6199
}

Final report

Approved for public release; distribution is unlimited

Prepared for $\begin{aligned} & \text { U.S. Army Corps of Engineers } \\ & \text { Washington, DC 20314-1000 }\end{aligned}$

Under Work Unit 32492 


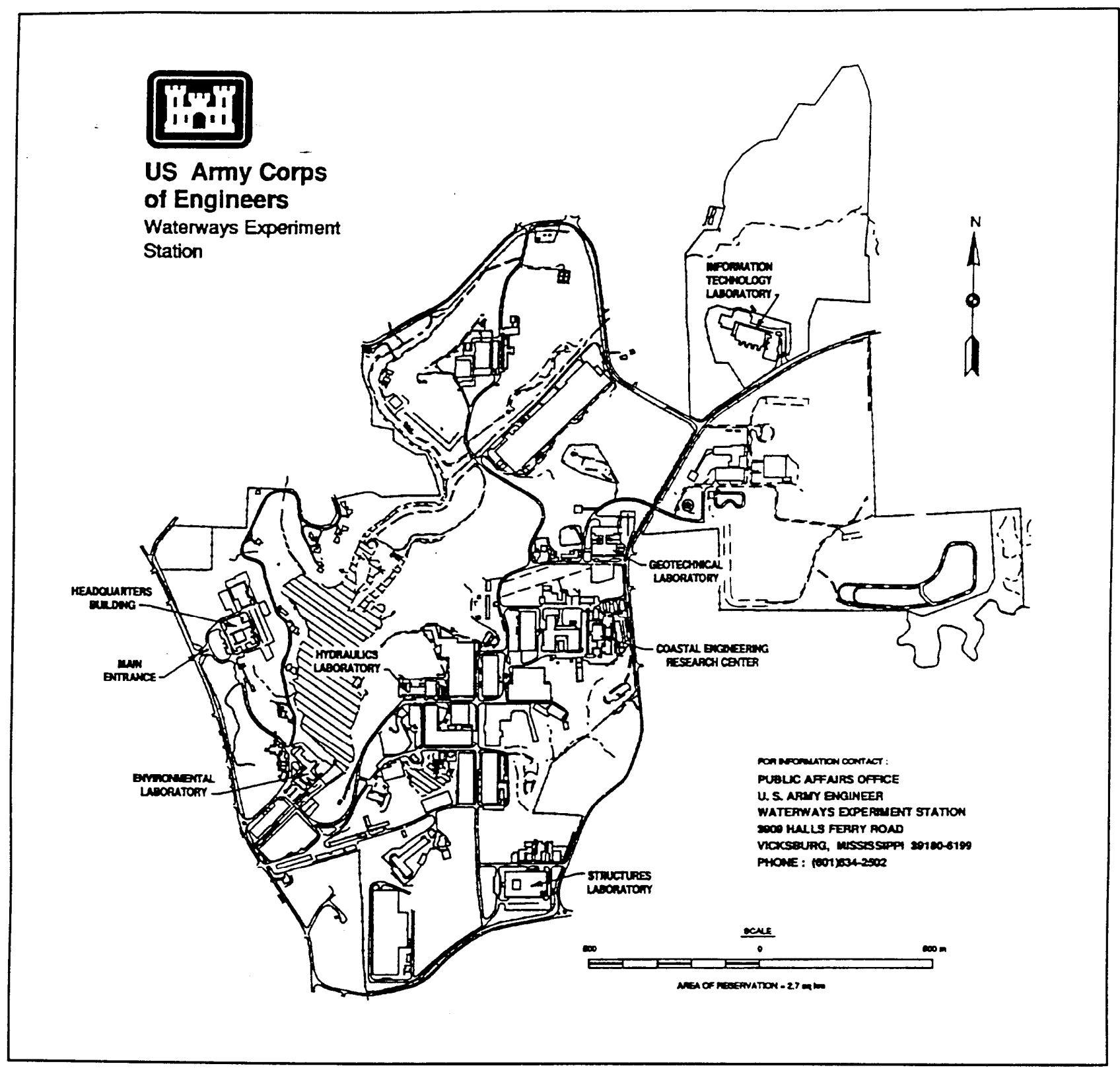

Waterways Experiment Station Cataloging-in-Publication Data

Vessel positioning, survey controls, and dredge monitoring systems : summary report for technical area 4 / compiled by Lyndell Z. Hales : prepared for U.S. Army Corps of Engineers.

73 p. : ill. ; $28 \mathrm{~cm}$. -- (Technical report ; DRP-95-9)

Includes bibliographic references.

1. Dredging - Management. 2. Dredging -- Instruments. I. Hales, Lyndell Z. II. United States. Army. Corps of Engineers. III. U.S. Army Engineer Waterways Experiment Station. IV. Dredging Research Program (U.S.) V. Series: Technical repon (U.S. Army Engineer Waterways Experiment Station); DRP-95-9.

TA7 W34 no.DRP-95-9 


\section{Contents}

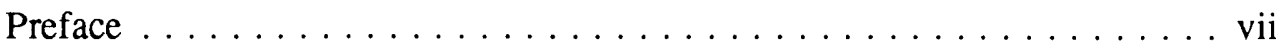

Conversion Factors, Non-SI to SI Units of Measurement $\ldots \ldots \ldots \ldots$ ix

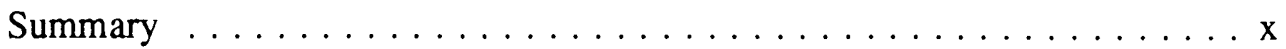

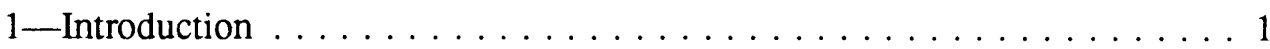

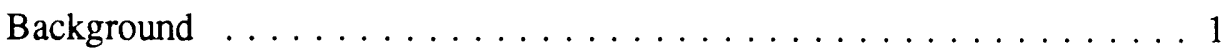

Report Organization ..................... 3

2-Integrated Vertical Control $\ldots \ldots \ldots \ldots \ldots \ldots \ldots \ldots$

ARTTES ............................ 5

Improvements to ARTTES by the DRP $\ldots \ldots \ldots \ldots \ldots \ldots \ldots$

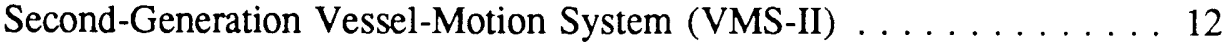

3-Horizontal/Vertical Positioning System Utilizing GPS Satellite

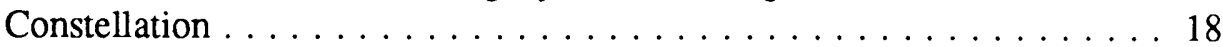

Present Surveying and Positioning Methodology . . . . . . . . . . 18

GPS . . . . . . . . . . . . . . . . . . . . . . . . . 19

Corps of Engineers Real-Time, On-the-Fly Differential GPS System . . . 23

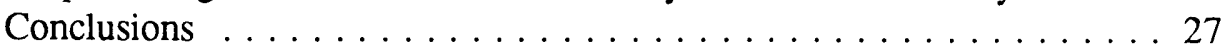

4-Production-Meter Technology $\ldots \ldots \ldots \ldots \ldots \ldots \ldots \ldots 28$

Dredge Production-Meter Use . . . . . . . . . . . . . . . . . . 28

Laboratory Tests . . . . . . . . . . . . . . . . . . . . . . . 30

Evaluation on Dustpan Dredge Jadwin . . . . . . . . . . . . . 33

Evaluation on Hopper Dredge Wheeler . . . . . . . . . . . . . . . . 37

5 -Silent Inspector $\ldots \ldots \ldots \ldots \ldots \ldots \ldots \ldots \ldots \ldots \ldots \ldots \ldots$

SI System Concept $\ldots \ldots \ldots \ldots \ldots \ldots \ldots \ldots \ldots \ldots \ldots \ldots$

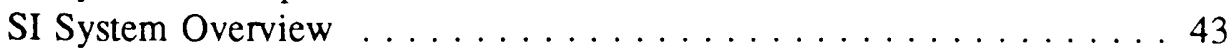

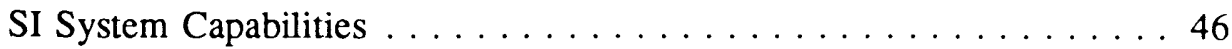

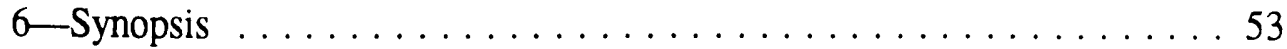

Integrated Vertical Control . .................... 53

Horizontal/Vertical Positioning System Utilizing GPS Satellite

Constellation ............................ 55 
Production-Meter Technology . . . . . . . . . . . . . . . 56

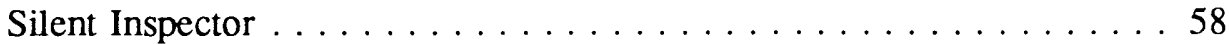

References ...........................660

SF 298

\section{List of Figures}

Figure 1. Comparison of ARTTES access periods to present procedure for $0.2-m$ threshold $\ldots \ldots \ldots \ldots \ldots \ldots \ldots \ldots$

Figure 2. Absolute and differential GPS ............. 22

Figure 3. Real-time OTF GPS ................. 23

Figure 4. Block diagram of OTF prototype system . . . . . . . 24

Figure 5. Schematic of information flow required by OTF system . . . 26

Figure 6. GWI instrumentation loop for testing dredge production

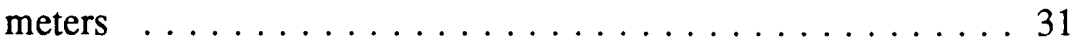

\section{List of Tables}

Table 1. Production-Meter Laboratory Test Conditions . . . . . . . . 31

Table 2. Largest Percent Difference from Control for Slurry Concentrations ..................... 32

Table 3. Influence of Dredge-Pump Speed on Production . . . . . . 35

Table 4. Influence of Water-Jet Pump Pressure on Production . . . . . 35

Table 5. Hopper Dredge Wheeler Load Study Comparison Data . . . . . 40 


\section{Preface}

This report summarizes research conducted by U.S. Army Engineer Waterways Experiment Station (WES) Dredging Research Program (DRP) Technical Area 4, "Vessel Positioning, Survey Controls, and Dredge Monitoring Systems," and the U.S. Army Topographic Engineering Center (TEC). The DRP was sponsored by Headquarters, U.S. Army Corps of Engineers (HQUSACE). Technical Monitors for Technical Area 4 were Messrs. Moody K. Miles, III, and Barry W. Holliday. Chief Technical Monitor was Mr. Robert H. Campbell (retired), HQUSACE.

This summary report was compiled by Dr. Lyndell Z. Hales, Coastal Engineering Research Center (CERC), WES, and was extracted essentially verbatim from Technical Area 4 reports.

Technical Area 4 studies were conducted by or under the following WES and TEC supervision:

CERC, WES - Dr. Andrew W. Garcia, Principal Investigator, Prototype Measurement and Analysis Branch (PMAB), Engineering Development Division (EED); Dr. Todd L. Walton, Jr., Coastal Structure and Evaluation Branch (CSEB), EED; and Mr. James Rosati, III, Principal Investigator, PMAB. Additional supervision was provided by Mr. William L. Preslan, Chief, PMAB; Ms. Joan Pope, Chief, CSEB; Mr. Thomas W. Richardson, Chief, EED; Mr. Charles C. Calhoun, Jr., Assistant Director, CERC; and Dr. James R. Houston, Director, CERC.

Hydraulics Laboratory (HL), WES-Ms. Virginia R. Pankow and Mr. Stephen H. Scott, Principal Investigators, Estuarine Engineering Branch (EEB), Estuaries Division (ED). Additional supervision was provided by Mr. William D. Martin, Chief, EEB; Mr. William H. McAnally, Jr., Chief, ED; Mr. Richard A. Sager, Acting Director, HL; and Mr. Frank A. Herrmann, Jr. (retired), former Director, HL.

Topographic Developments Laboratory (TDL), TEC-Mr. Kevin P. Logan, Mr. Carl A. Lanigan, and Ms. Sally L. Frodge, Principal Investigators, under the direction of Mr. Steven R. DeLoach, Precise Survey Team Leader, Surveying Division (SD). Additional supervision was provided by Mr. Peter J. Cervarich, Chief, SD; and Mr. Regis J. Orsinger, Director, TDL. 
Dr. Garcia and Mr. George P. Bonner, Chief, Instrumentation Services Division, WES, were the Technical Area Managers for Technical Area 4.

Mr. E. Clark McNair, Jr., CERC, and Dr. Hales were Manager and Assistant Manager, respectively, of the DRP. Dr. Houston and Mr. Calhoun were Director and Assistant Director, respectively, of CERC, which conducted the DRP.

At the time of publication of this report, Director of WES was Dr. Robert W. Whalin. Commander was COL Bruce K. Howard, EN.

COL David F. Maune was TEC Commander and Director, and Mr. Walter E. Boge was TEC Technical Director when these studies were accomplished.

For further information on this report or on the Dredging Research Program, please contact Mr. E. Clark McNair, Jr., DRP Program Manager, WES, at (601) 634-2070.

The contents of this report are not to be used for advertising, publication, or promotional purposes. Citation of trade names does not constitute an official endorsement or approval of the use of such commercial products. 


\section{Conversion Factors, Non-SI to SI Units of Measurement}

Non-SI units of measurement used in this report can be converted to SI units as follows:

\begin{tabular}{||l|l|l||}
\hline Multiply & By & To Obtain \\
\hline \hline cubic yards & 0.7645549 & cubic meters \\
\hline feet & 0.3048 & meters \\
\hline feet per second & 0.3048 & meters per second \\
\hline gallons per minute & 63.094578 & cubic centimeters per second \\
\hline inches & 2.54 & centimeters \\
\hline inches & 25.4 & millimeters \\
\hline knots & 1.852 & kilometers per hour \\
\hline long ton (2,240 lb) & 1.016 .96 & kilograms \\
\hline miles (U.S. nautical) & 1.852 & kilometers \\
\hline miles (U.S. statute) & 1.609347 & kilometers \\
\hline pounds (force) per square inch & 6.894757 & kilopascals \\
\hline pounds (force) per cubic foot & 0.01603 & grams per cubic œentimeter \\
\hline
\end{tabular}




\section{Summary}

This report summarizes research conducted under the U.S. Army Engineer Waterways Experiment Station Dredging Research Program Technical Area 4, "Vessel Positioning, Survey Controls, and Dredge Monitoring Systems."

Research was conducted to address the need for measuring and reporting offshore onsite water levels and for an enhanced vessel-heave system for dredging purposes. The development of a real-time, on-the-fly, 3-D navigation system with accuracy of $1 \mathrm{dm}$ (4 in.) for surveying and dredging based on a NAVSTAR global positioning system (GPS) is presented. Laboratory and field tests of production meters for dredges were conducted to determine reliability under different dredging conditions. Concept development and operational aspects of a silent inspector for monitoring contract hopper dredges are also presented.

"Integrated Vertical Control" enhanced the automated real-time tidal elevation system (ARTTES) to prevent access denial when threshold conditions for surveying are exceeded but may not be severe enough to preclude dredging operations. Practical aspects of short-term meteorological conditions were taken into account to allow some degree of engineering judgment to be considered. Vessel-motion (heave) compensators also were enhanced to allow operation in the frequency domain where commercially available components can be utilized. A procedure for estimating future wave data was developed.

"Horizontal/Vertical Positioning System Utilizing GPS Satellite Constellation" developed real-time on-the-fly (OTF) differential global positioning system (DGPS) technology so that only one fixed reference station of known coordinates ( $\mathrm{x}, \mathrm{y}, \mathrm{z}$ position) located every $20 \mathrm{~km}$ would provide the user with 2-cm (1-in.) accuracy (far better than the specification goal of decimeter (4-in.) accuracy) for hydrographic surveying and dredging-quantity determination for contract estimation and final-payment computations. It was demonstrated that real-time OTF is as easy to provide as code phase DGPS within the current range limitations of $20 \mathrm{~km}$.

"Production Meter Technology" performed laboratory tests of dredge production meters (velocity and density) identified in a worldwide survey as presently being used onboard operating dredges. These tests evaluated the reliability of the production meters under controlled conditions of slurry type, concentration, and flow and pipe orientation. Field tests were also conducted 
aboard the dustpan dredge Jadwin and the hopper dredge Wheeler to determine production-meter reliability of operation under two different dredged material conditions (sand and silt sediments).

A "silent inspector" (SI) system was developed to automatically log data from instruments generally maintained aboard contractor-operated hopper dredges. Dredging activities were recorded to compute the quantity of material retained and to provide summaries of this information in both tabular and graphic displays. The SI produces a factual record of the dredge's activities that is sufficient for dredging inspectors to accurately assess contract performance even in the absence of a full-time onboard inspector. The SI was successfully tested aboard the hopper dredge Essayons under real operating conditions. 


\section{Introduction}

The U.S. Army Corps of Engineers is involved in virtually every navigation dredging operation performed in the United States. The Corps' navigation mission entails maintenance and improvement of about $40,000 \mathrm{~km}$ of navigable channels serving about 400 ports, including 130 of the Nation's 150 largest cities. Dredging is a significant method for achieving the Corps' navigation mission. The Corps dredges an average annual 230 million cu $\mathrm{m}$ of sedimentary material at an annual cost of about $\$ 400$ million. The Corps also supports the U.S. Navy's maintenance and new-work dredging program (McNair 1989).

\section{Background}

\section{Genesis of the Dredging Research Program}

Significant changes occurred in the conduct of U.S. dredging operations and the coordination of such dredging with environmental protection agencies as a result of the National Environmental Policy Act of 1969. Subsequent Federal legislation authorized a study of the ability of private contractors to perform the Nation's required navigation dredging activities. That study determined that, from national emergency considerations, only a minimal Federal dredge fleet was necessary, and the bulk of hopper-dredge activities shifted from the once large Corps fleet to private sector contract hopper dredges (Hales 1995).

A long period in which the Corps' dredging activities consisted almost totally of maintaining existing waterways and harbors changed with passage of the Water Resources Development Act of 1986. This legislation authorized major deepening and widening of existing navigation projects to accommodate modern Navy and merchant vessels. Future changes in dredging are not expected to be any less dramatic than those which occurred in recent years. The Corps will continue to be challenged in pursuing optimal means of performing its dredging activities. Implementation of an applied research and development program to meet demands of changing conditions related to Corps dredging activities and the generation of significant technology that will be adopted by all dredging interests are means of reducing the cost of dredging the Nation's waterways and harbors. 


\section{Research program}

The concept of the Dredging Research Program (DRP) emerged from leadership of Corps of Engineers Headquarters (Navigation and Dredging Division and Directorate of Research and Development (CERD)) in the mid-1980s (McNair 1988). It was realized early in the program development that research should be directed toward addressing documented deficiencies identified by the primary Corps users, namely the field operating Division and District offices. Problems identified by the field offices were formulated into specific applied research work tasks describing objectives, research methodologies, user products, and time/cost schedules. CERD delegated primary responsibility for developing the DRP to the U.S. Army Engineer Waterways Experiment Station (WES). The 7-year, \$35-million DRP, initiated in FY88, achieved all major milestones, goals, and objectives scheduled in the program-planning process.

A major DRP objective was the development of equipment, instrumentation, software, and operational monitoring and management procedures to reduce the cost of dredging the Nation's waterways and harbors to a minimum consistent with Corps mission requirements and environmental responsibility. The DRP consisted of the following five technical areas, from which many distinct products were generated and annual and one-time direct and indirect benefits were quantifiable.

a. Technical Area 1. Analysis of Dredged Materials Disposed in Open Water.

b. Technical Area 2. Material Properties Related to Navigation and Dredging.

c. Technical Area 3. Dredge Plant Equipment and Systems Processes.

d. Technical Area 4. Vessel Positioning, Survey Controls, and Dredge Monitoring Systems.

e. Technical Area 5. Management of Dredging Projects.

\section{Technical Area 4}

Objectives of Technical Area 4, "Vessel Positioning, Survey Controls, and Dredge Monitoring Systems," included (a) providing enhancements to an automated real-time tidal elevation system (ARTTES) and developing a secondgeneration frequency-domain-based vessel-motion (heave) system (VMS-II), (b) developing a real-time 3-D global positioning system (GPS) carrier phasebased positioning system for hydrographic surveying and dredging with 
accuracy better than $1 \mathrm{dm}$ (4 in.), ${ }^{1}$ (c) evaluating dredge production-meter performance by controlled laboratory tests and by tests of both dustpan and hopper dredges under actual field operating conditions, and (d) developing a silent inspector (SI) system to automatically log data from instruments generally maintained aboard contractor-operated hopper dredges and provide summaries of these data in both tabular and graphic form to better assess contractor performance and adherence to contract terms. Research areas of Technical Area 4 included:

a. Integrated vertical control.

b. Horizontal/vertical positioning system utilizing GPS satellite constellation.

c. Production meter technology.

d. Silent inspector.

\section{Report Organization}

Chapter 2 of this report describes enhancements to ARTTES by the development of a real-time universal system for measuring and reporting offshore onsite water levels. This research also produced VMS-II, which used commercially available sensors for significant reduction in fabrication cost.

Chapter 3 describes the development of a GPS carrier phase-based positioning system for surveying and dredging. The system provides real-time 3-D positions with accuracy better than $1 \mathrm{dm}$ (4 in.) over ranges up to $20 \mathrm{~km}$ from a single reference station without static initialization. The project has passed from concept development, through feasibility studies, through resolution of carrier ambiguities on the fly, to final system integration.

Chapter 4 presents comparisons of laboratory tests conducted on dredge production meters (doppler and magnetic velocity meters and nuclear density meters) versus controlled standards to determine the reliability of the meters while operating with different types of slurry material. Field tests were conducted aboard the dustpan dredge Jadwin operating in sand materials using doppler velocity and nuclear density meters and aboard the hopper dredge Wheeler operating in silt and clay materials using magnetic velocity and nuclear density meters.

Chapter 5 describes concept development and operational aspects of the SI system for automatically monitoring activities aboard a contractor-operated hopper dredge. The SI collects and records measurement from shipboard

\footnotetext{
1 A table of factors for converting non-SI units of measurement to SI units is provided on page ix.
} 
sensors, calculates the dredging activity being performed and the weight of material recovered in tons dry measure, and displays this information through standardized tabulations and graphic data displays.

Chapter 6 is a synopsis of technical reports pertaining to research and technology development by the DRP to (a) better determine vessel horizontal and vertical positioning on the Earth's surface for survey control, and precise vertical location with respect to a stationary datum for hydrographic surveying to minimize overdredging because of tidal variations, (b) enhance dredging through production-meter technology, and (c) ensure that contractor-operated hopper dredges adhere to contract requirements. 


\section{Integrated Vertical Control}

Dredging operations, as well as dredge monitoring and contract payment, require the measurement of accurate bathymetry referenced to a static datum. Real-time availability of the mean water level and compensation for the waveinduced vertical motion of the vessel are required to accomplish these activities. Objectives of integrated vertical control research were to provide enhancements to ARTTES by developing a real-time universal system for measuring and reporting offshore onsite water levels, and developing a frequency-domain vessel-motion (heave) system that used commercially available sensors. The enhanced ARTTES system is rugged, supports multiple dredges and survey vessels operating in a given area, and is interfacecompatible with existing typical Corps hydrographic and data-logging acquisition systems. The system employs internal checks and user notification diagnostics extensively to minimize routine user/system interaction.

\section{ARTTES $^{1}$}

A long-standing problem associated with coastal and offshore dredging operations has been accounting for tidal effects in hydrographic surveys and in the dredging process to ensure that design channel depth has been reached and to aid determination of the quantity of material moved to compute payment. The shift from Corps owned and operated dredges to contract dredging operations brought with it the need for more accurate specification of channel cross sections and dimensions. However, more accurate channel specifications are relevant only if means exist to verify that the specifications were met. In addition, requirements to dredge to greater depths and greater distances offshore have emphasized the monetary consequences of inaccurate channel measurements. Because credible water-level data typically are scarce or absent at offshore locations, disputes between the Corps and contractors have arisen as to the amount of material dredged and payment due (Garcia 1990).

An engineering tool was required to provide accurate water surface elevations, thus reducing the need for overdepth dredging. Such a system had to be

1 This section of Chapter 2 was extracted from Garcia (1990), Lillicrop et al. (1991), and Borgman, Garcia, and Walton (1993). 
cost-effective and at the same time relatively easy to install, maintain, and operate. Consideration was given to developing permanent or semipermanent towers equipped with a water-level sensor to be located along a navigation channel, thus providing water-levei elevations along the project area. However, this alternative was rejected due to high initial costs, potential hazard to navigation, and expected vandalism and consequent high maintenance costs (Lillycrop et al. 1988).

At the request of the U.S. Army Engineer District, Jacksonville, an alternative system was developed by WES to support deepening of the entrance channel to the U.S. Navy Trident Submarine Base, Kings Bay, GA. The design project depth of $46 \mathrm{ft}$ mean low water required an entrance channel extending approximately 13 miles seaward of the ocean end of existing jetties. Because the tidal-elevation system will be used by contractors as well as Corps survey vessels, the system was designed for relatively unskilled persons with little ability for hands-on intervention and little investment in user equipment. The system was designated the automated real-time tidal elevation system (ARTTES).

\section{ARTTES concept}

ARTTES allows virtually unlimited numbers of users to obtain instantaneous tidal-elevation data over a designated area. It is based on a predictorcorrector method and consists of a high-precision water-level sensor linked to a VHF transmitter that continuously broadcasts the water level as measured at some location in the designated area. Users have a VHF receiver linked to a lap-type or desktop computer. Resident on the computer is communication/ computation software that predicts the tidal level at a user-specified location based on data previously acquired within the designated area. The predicted water level is corrected for nontidal (meteorological) effects using data received via the radio transmitter and is then displayed to the operator. The system permits highly repeatable elevation control during offshore surveys. Moreover, use of the system allows dredge operators to make online adjustments for changes in water level, thus minimizing the need to overdredge.

Prior to an ARTTES installation, tidal measurements must be collected along the navigation channel and at a permanent nearshore measurement location. These data are used to determine the values of harmonic constituents needed for a tide-prediction model. Two to four self-recording pressure gauges are temporarily placed along the channel to collect several months of data. The total number of gauges necessary is dependent upon local conditions such as navigation channel configuration, bottom topography, and inlet parameters.

Data from the permanent pressure-gauge location and the temporary gauges are used to determine the five constituents used in the tide-prediction model. These constituents were found to account for the preponderance of the variance along the lower east coast of the United States where four ARTTES are 
presently in operation (Kings Bay, GA; Brunswick, GA; Savannah, GA; Charleston, SC).

The ARTTES concept is based on three broad assumptions: (a) the total annual water-level variance due to the astronomical tide is large compared to other effects; (b) meteorological conditions are spatially large compared to the area of operation; and (c) over the channel distances, changes in sea surface elevation can be well approximated using linear interpolation. ARTTES is composed of two primary subsystems: the water-level measurement system (WLMS) and the receiver system (RS).

\section{Water-level measurement system}

The purpose of the WLMS is to transmit a nearshore real-time water-level measurement referenced to a datum. The WLMS is composed of an offshore pressure transducer, a shore-connected cable, a shore microcomputer box, a high-power VHF FM transmitter, and a tower-mounted omnidirectional VHF antenna. The water-level measurement is transmitted over a standard VHF high-band frequency using standard Bell 103 modem tones. Data are encoded in the real-time simplex protocol (RTSP), which permits multiple receiving stations to simultaneously receive the water-level measurements error free. Simplex implies that the transmissions are one-way only. There is no requirement for the receiving units to transmit to the shore site, thereby eliminating the cost and problems associated with high-power transmitters at the receiving site. The RTSP protocol uses a packet radio technique that provides for multiple water levels, wave measurements, and other environmental parameters to be broadcast on the same frequency. Additional measurements may be added or removed without affecting others. RTSP also provides diagnostic packets that will indicate the nature of any system malfunction (Lillycrop et al. 1991).

\section{Recelver system}

RS components include a VHF scanner/receiver, Bell 103 compatible modem, a portable computer, and real-time tide prediction (RTTP) software. An off-the-shelf scanner is used to receive the transmitted data packet and pass it to the computer where the data are processed through the RTTP model. The scanner/receiver used with the four operational ARTTES systems is the commercially available Bearcat scanner. Any portable computer that supports BASIC can be used to run the RTTP tide-prediction software. The Tandy 100, a Radio Shack laptop computer with a built-in Bell 103 compatible modem, has been used to date. The ARTTES receiver system is not limited to any of these commercial systems and can operate on any system with a similar configuration. The RS can utilize an existing onboard survey computer interfaced with a positioning system and a fathometer (Lillycrop et al. 1991). 


\section{Applicabllity}

ARTTES is applicable only to nearshore open-ocean areas (i.e., seaward of the mouth of a river or jetty system up to approximately 20 miles offshore). Dredging and survey operations requiring tide data within the reaches of jetties or into estuaries and rivers are better served using other techniques or systems. The limit of 20 miles is due to the present type of radio transmitter being used. A more powerful transmitter could be used to extend that range.

Bathymetry of the candidate area should be reasonably well represented by one or a series of linear slopes. The series of slopes should rise monotonically in the onshore direction. The channel area should be free of deep marine canyons or very shallow shoals, especially any that are exposed during only part of the normal tide cycle. Current bathymetry or navigational charts of the vicinity are usually adequate to determine whether the area is suitable for ARTTES application from a bathymetric standpoint.

At least 80 percent of the annual water variance at the candidate site must be due to the astronomically forced tide. National Ocean Service tide data for the general vicinity can be used to determine whether this criterion is met. Most locations along the coasts of the Atlantic and the Gulf of Mexico and many along the Pacific coastline of the continental United States meet this criterion.

There should be significant differences in the range and/or phase of the tide along the extent of the channel. Differences of 15 to 20 percent in range are common in shallow coastal areas where dredging often occurs. Where the tide range is small (for example, $2 \mathrm{ft}$ ), differences may be only a few tenths of a foot, perhaps small enough to be of no significant concern. Where the tide range is greater (for example, $6 \mathrm{ft}$ ), differences may exceed $1 \mathrm{ft}$ and have to be considered if accurate survey and dredging are to be conducted.

\section{Improvements to ARTTES by the DRP}

As presently implemented, ARTTES uses a completely deterministic procedure for predicting the tide. When the differences between the predicted tide and observed level exceed some predetermined value, user access to the system is denied. The difference between measured and predicted values (at the measurement site) is an indicator of the validity of the assumption that the astronomical tide component is dominant. Dominance means that the astronomical component of the water-level variation is approximately one order of magnitude greater than the sum of the remaining components. Zero or small differences (a few centimeters) mean that the assumption is robustly met within the entire specified area of operation and that users can be confident of the broadcast system values. When differences between the predicted and observed values increase, as is typically the case during periods of disturbed weather, the assumption of dominance of the astronomical tide component grows 
increasingly weak. At some difference between the predicted tide and observed water level, the assumption of tidal dominance is considered to be invalid for the desired degree of water-level accuracy over the area of operation.

Periods of user-access denial usually occur when sea conditions are unfavorable or unsuitable for survey operations. Dredging operations, however, may continue in weather conditions unsuitable for survey operations. Because ARTTES may be used by dredge operators, it is desirable to minimize periods of user-access denial.

The present procedure for predicting the tide at the sensor location is based upon the harmonic method of tide analysis and prediction. Water-level data at the desired location are acquired for several months, analyzed to determine the amplitude and phase of the dominant tidal constituents, and then used to predict the tide. Data required for tide prediction are obtained prior to initial operation of an ARTTES. Although water-level data at the sensor site are recorded and available once an ARTTES begins operation, analysis of these data by the harmonic method and incorporation of the results into the prediction routine presently being used typically result in little improvement in the predictions. The lack of improvement in tide prediction stems from the fundamental assumption underlying the harmonic method, namely that the tide is described by a sum of sine or cosine functions that represent the astronomically forced component. However, a portion of the water-level record is not described by this sum. That portion is termed the residual. Most of the residual is the result of short-term meteorological effects.

\section{ARTTES enhancement technique}

The approach used by Borgman, Garcia, and Walton (1993) for DRP improvements to ARTTES predictions may be described as "hybrid" in that the astronomically forced component of the tide is analyzed and predicted in the traditional manner (harmonic analysis), while the short-term meteorological component (residual) is analyzed and predicted via statistical techniques. The two statistical techniques investigated are conventionally called Kriging and autoregression, respectively. Kriging is based on the minimization of expected square error, subject to the constraint that the estimation is unbiased. Autoregression is based on minimization of expected square error only. Both methods assume that the estimate is covariance-stationary.

\section{Application of Kriging and autoregression}

Application of either the Kriging or autoregression procedure requires the user to specify two parameters related to the physical situation. The first parameter is the threshold value of the difference between observed and predicted water levels (residual) beyond which ARTTES data may be degraded. The second parameter is the permissible duration of the threshold 
exceedence. ${ }^{1}$ The threshold value is chosen using engineering judgment and knowledge of residual values from previous water-level monitoring at the site. The goal is to choose a value such that smaller residuals represent meteorological effects that are large enough in scale to have a uniform effect over the specified area of ARTTES operation. The assumption of spatial uniformity becomes somewhat questionable for residuals exceeding the threshold.

In the presently operational version of ARTTES, user access is denied whenever the residual exceeds a preset limit, even if the threshold is just slightly exceeded. The Kriging or autoregressive procedures provide an estimate of the duration of a specific threshold exceedence. Magnitude of the estimate is related to the size and severity of the event causing the deviation from predicted water levels, thereby providing an objective basis for a decision to use or ignore the system during periods of degraded data.

The essence of this suggested new approach by Borgman et al. (1993) is that the assumption of spatial uniformity is likely to be met even though the threshold is exceeded, if data from the recent past are used to distinguish short-duration events from long-duration events that alter the fundamental physical setting. Alteration of the physical setting for extended periods affects the site-specific tidal amplitude and phasing relationships upon which the ARTTES calculations are based, thereby producing potentially erroneous values. The duration limit is based upon knowledge of the history of the site's water-level data and engineering judgment.

By using combinations of levels of threshold exceedence and duration, practical aspects of the dredging process may be taken into account. Because dredges are costly to operate, data-access denial should occur only when the potential consequences warrant (i.e., data degraded to a known degree are usually preferable to no data at all). For example, the dredging supervisor may deem it preferable to permit a relatively high level of threshold exceedence for a relatively short time (say, an estimated duration of $1 \mathrm{hr}$ ) rather than to deny access.

Two applications were made of the Kriging and autoregressive procedures by Borgman, Garcia, and Walton (1993). The first was a synthesized time series of known statistical properties. The threshold and duration values for this application were $0.25 \mathrm{~m}$ and 10 time-steps, respectively. In general, periods of access denial for this simulation were not found until the latter part of the time series, first at time-step 1,200 and again at time-step 1,600. Beginning at time-step 1,637, there was an extended period of access denial that continues until time-step 1,683, or 47 time-steps. Examination of the input time series for this period shows residual values exceeding the threshold, often by factors of two or more. Moreover, comparison of the input and output time series shows that short periods of threshold exceedence in the input time series

\footnotetext{
1 Editor's note: The term threshold exceedence is used to identify the point beyond which measured values exceed a predetermined limit.
} 
were smoothed out by the low-pass filter and therefore did not invoke application of the Kriging procedure.

The Kriging and autoregressive procedures also were applied to a residual time series acquired at an operating ARTTES system. The time series was typical of periods when weather conditions are unsuitable for survey-vessel operation but when dredges are likely to continue operating. The threshold value and acceptable duration for this application were set at $0.2 \mathrm{~m}$ and $3 \mathrm{hr}$, respectively. Results of the applied Kriging procedure are shown in Figure 1. The autoregressive procedure produced almost identical results. Both periods during which user access was denied under the present system and the Kriging procedure are illustrated. Note the shorter period of user denial with the Kriging procedure when compared with the existing system. As with the synthesized time series, a low-pass filter was applied to the input time series to remove high-frequency components before applying the Kriging or autoregressive procedures. Although the Kriging procedure has a slightly larger rootmean-square error than the autoregression procedure, the Kriging estimate is unbiased whereas the autoregression estimate shows bias.

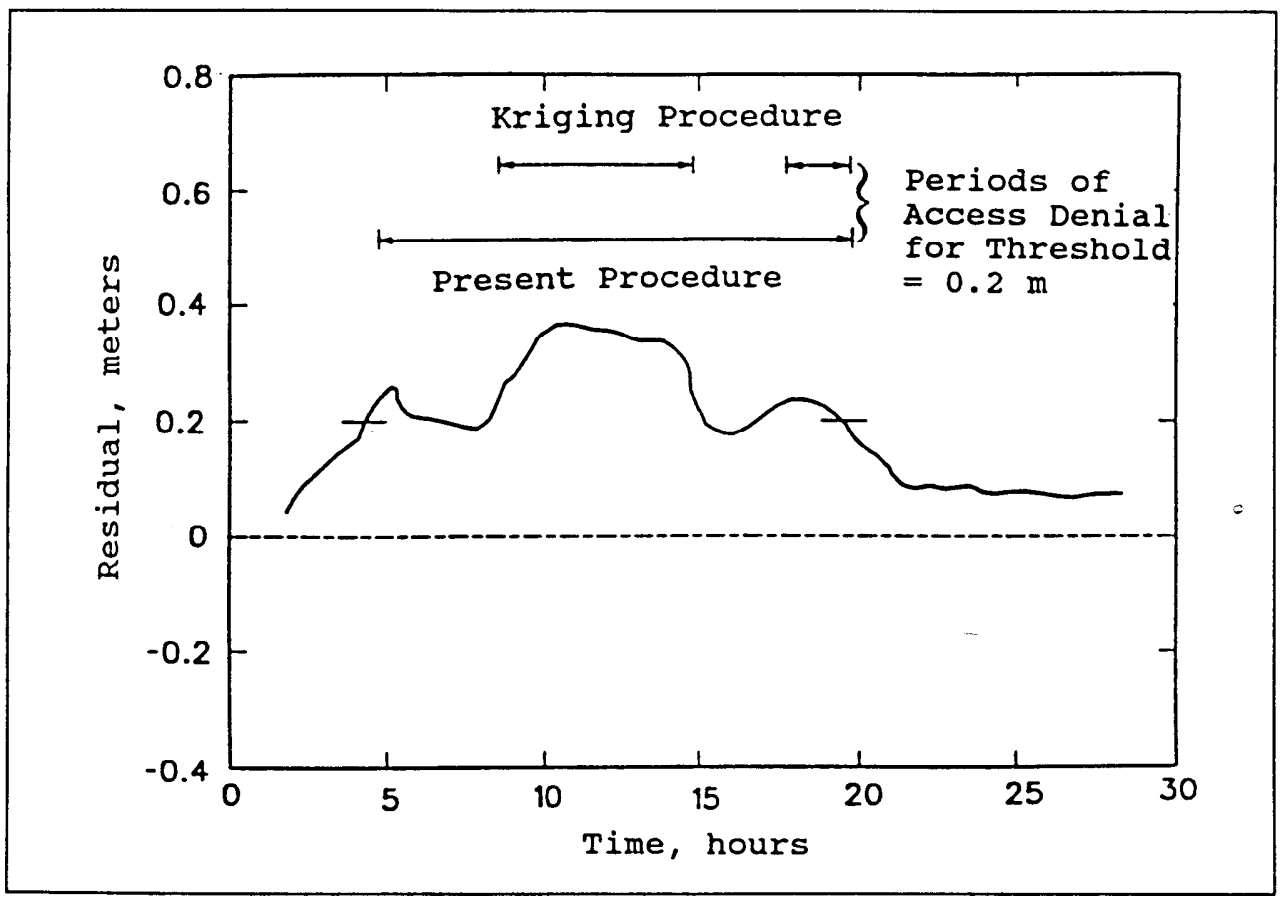

Figure 1. Comparison of ARTTES access periods to present procedure for 0.2-m threshold 


\section{Second-Generation Vessel-Motion System (VMS-II)}

VMS's (sometimes termed heave compensators) for use in hydrographic survey applications presently exist in various forms. However, the current generation of VMS's typically operate in the time domain, which results in inherent limitations, particularly when applied to small vessels operating in coastal waters. Moreover, present systems are generally based upon customdesigned and specially manufactured electromechanical components. The relatively small market for such systems tends to increase the unit cost.

Research conducted by Carter et al. (1995) was directed toward development of a frequency-domain-based second-generation VMS (VMS-II) that uses commercially available sensors. Use of commercially available sensors reduces the unit cost of a VMS and is made possible by embedded system software executed by high-speed digital signal-processing microcircuits. The research focused on development of the configuration of the circuitry and signal-processing techniques required to achieve the desired performance.

VMS-II is unique in that estimates of the real-time vertical motion are derived by double integration of the vertical component of acceleration in the frequency domain. Integration in the frequency domain permits virtually instantaneous estimates of the vertical displacement with no phase lag. Moreover, the system is inherently stable with no feedback and therefore is immune to impulse effects. A prototype version of the system performed successfully in the laboratory environment. Field trials aboard several types of survey vessels under various sea conditions are ongoing.

\section{TIme-domain versus frequency-domain integration}

In a number of common operations conducted from floating vessels or platforms, it is useful or necessary to know the motion of the vessel as it responds to external forces (i.e., waves and winds). To reduce errors during these operations, vessel motions must be measured in real-time or with very little time lag. For example, a $100-\mathrm{msec}$ lag in calculating the wave-induced heave for an actual heave of $1.5-\mathrm{m}$ amplitude with a $10-\mathrm{sec}$ period could produce an error of $9.4 \mathrm{~cm}$.

The most useful form of a heave-measuring system is an inertial sensor and a double integrator. In principle, such a system is very simple with a vertical accelerometer mounted in an assembly with two clinometers to measure pitch and roll. The accelerometer is mounted with its vertical axis normal to the deck of the vessel with one clinometer measuring roll about the vessel's

1 This section of Chapter 2 was taken from Carter et al. (in preparation) and Borgman and Scheffner (1991). 
longitudinal axis while the other measures pitch around the vessel's lateral axis. With such an arrangement, the true vertical acceleration of the vessel can be computed from the following relationship, which assumes negligible accelerations in lateral directions:

$$
\text { True vertical acceleration }=\frac{\text { Measured Acceleration }}{\cos (\text { pitch }) \times \cos (\text { roll })}
$$

\section{Time-domain Integration}

After having corrected vertical acceleration for errors caused by pitch and roll, corrected vertical acceleration must be integrated twice with respect to time to produce vertical-motion displacement (i.e., heave). This double integration has been performed in the time domain for many years using both analog and digital techniques. Unfortunately, all techniques that have been developed and display long-term stability also produce an unavoidable phase lag. In many applications this phase lag is acceptable; however, for real-time applications, the phase lag is unacceptable. To date, no method of continuously double integrating a real-time data stream in the time domain has proven acceptable in this most demanding of applications.

\section{Frequency-domain integration}

Double integration of the vertical acceleration in the frequency domain is appealing, as the phase lag can be eliminated. Use of the Fast Fourier Transform (FFT) provides a rapid method for transforming a data set from the time domain to the frequency domain. Once in the frequency domain, the Fourier coefficients can then be multiplied by constants proportional to $1 /$ frequency $^{2}$ to provide the Fourier transform of the double-integrated time series. This Fourier transform can then be inverted to produce a time-series estimate of heave.

This very useful result is tempered by a restriction that applies to all applications of a Fourier transform: a Fourier transform is strictly applicable to periodic functions or to those that can be made to appear periodic. For nonperiodic functions, the Gibb's phenomenon will produce large errors in the inverted transform except at the center of the data set. As real-time applications require the data point of interest to be at the end of the data set, the error produced by the Gibb's phenomenon would appear to make double integration in the frequency domain unusable for determining vessel heave. VMS-II is designed around a novel approach that eliminates or minimizes the errors produced by the Gibb's effect so that double integration of the vertical acceleration in the frequency domain can be utilized to produce real-time heave with acceptable error levels. 


\section{Future data sets for VMS-II}

Errors that occur in the determination of heave through double integration of vertical acceleration in the frequency domain can be eliminated or drastically reduced if the data point to be evaluated is at the center of the data set. This can easily be done with post-processed data; however, it cannot be done in real-time as the point of interest is always at the leading end of the data set. To get around this problem, VMS-II utilizes a unique approach that enables the point of interest to be at the center of the data set being analyzed.

Placing the data point of interest at the center of a real-time data set requires data that have not yet been measured. VMS-II utilizes a method for developing so-called "future" data that have the same statistical properties as the unknown data, based upon the assumption that the data are stationary in the mathematical sense. These future data can then be joined to the real data in such a manner that the most recent data point is in the center of the combined data set and the first and second derivatives are continuous across the two data sets. Frequency domain double integration can then be applied to the combined data set to produce heave estimates that have very little error.

\section{Developing future data sets}

A practical approach to providing estimates of future data was developed by Borgman and Scheffner (1991). The process of developing future data begins by constructing an extrapolation of the real data into the future with the data point of interest being the center of the data set composed of the real and future data. The first step in this process is to copy the existing data set into the future in what is called the unconditional extrapolation of the data. This step results in a discontinuity between the data point of interest and the following data point. The second step utilizes a smoothing technique that uses statistical data from a larger real data set to condition the transition region starting with the first future data point. The result of this smoothing is a data set with the discontinuity removed and the conditioned data flowing smoothly into the unconditioned data.

\section{VMS-II implementation problems and solutions}

Implementation of the hardware and software required to apply the techniques developed by Borgman and Scheffner (1991) presented several problems that had to be solved in the VMS-II.

a. A real data set of 1,024 data points must be placed end-to-end with itself to form an unconditioned data set of 2,048 points in which the data point representing the current time is at its center. To allow the FFT to perform properly, the discontinuity at the joint between the two sets of data must be smoothed by conditioning the simulation. This smoothing requires that a matrix $\mathrm{M}=\mathrm{C}_{21} \mathrm{C}_{11}+$ exist before the 
smoothing, where $C_{21}$ is the transpose of the cross covariance matrix $\mathrm{C}_{12}$ and the $\mathrm{C}_{11}+$ matrix is the Moore-Penrose generalized inverse of the covariance matrix $\mathrm{C}_{11}$.

$b$. The Fourier transform of the combined conditioned data set must be computed, multiplied by the transfer function to obtain the Fourier transform of the second integral in time, and the inverse Fourier transform computed. The 1,023rd data point in the resulting data set is the current estimate of heave.

$c$. Tasks $a$. and $b$. above must be executed in the time between the required real-time heave estimates. This time interval for a real-time heave system will typically be between 50 and $150 \mathrm{msec}$. As the number of floating point operations required by these two operations is on the order of $10^{6}$, both processor speed and algorithm efficiency are extremely important.

d. The matrix $\mathrm{M}$ used to condition the simulation must be periodically regenerated. Ocean wave motion is typically stationary in the mathematical sense for several minutes. However, the sea state as seen by a moving vessel is also dependent upon the speed and heading of the vessel and is subject to change in a short period of time. For example, a survey vessel may change course by $180 \mathrm{deg}$ in a $20-\mathrm{sec}$ period. This would result in the apparent wave celerity changing by twice the vessel's speed in $20 \mathrm{sec}$. The conditioning matrix $M$ must be regenerated in a period that is short with respect to the sea state that is observed by the moving vessel. The system regenerates the $M$ matrix approximately every $1.8 \mathrm{sec}$.

Problems in the practical application of the future data technique can be divided into two categories: memory requirement and computational time.

Memory requirement. As with most digital signal processes, the bandwidth of the data is the controlling factor. Heave data of interest have a maximum period of approximately $20 \mathrm{sec}$; thus, the data must be sampled for a total time of more than $40 \mathrm{sec}$ to calculate the mean and covariance function. A data sample length 2.5 times the longest heave period is a realistic requirement.

The overlap of the two data sets that are combined to form the unconditioned extrapolation must also extend over a time period of 2.5 times the longest period expected in the data. To obtain heave data that are useful for survey corrections, a sampling rate between 8 and 15 samples per second is required. At such rates, the overlap will contain approximately 500 data points and the $C_{11}, C_{21}$, and $C_{11}+$ matrices would each contain 250,000 elements. Such massive arrays could not be accommodated within practical equipment.

Borgman and Scheffner (1991) developed a technique for reducing the sampling rate for the statistical functions that is less than the sampling rate for 
the heave estimation. As an example, let the primary data be sampled at $10 \mathrm{~Hz}$ and let $\mathrm{f}_{\min }$ and $\mathrm{f}_{\max }$ be 0.143 and 0.25 , respectively. The maximum and minimum periods are then 7 and $4 \mathrm{sec}$; therefore, the 7 -sec period requires that data for the covariance extend over $17.5 \mathrm{sec}(2.5$ times 7$)$. If this interval were sampled at the primary rate of $10 \mathrm{~Hz}$, the $\mathrm{C}_{11}$ matrix would be $175 \times$ 175 , which would be very unwieldy. The sampling rate for the covariance matrix can be reduced to 2.2 times $\mathrm{f}_{\max }$ (Borgman and Scheffner 1991) (2.2 times 0.25 ) for a sampling period of $1.82 \mathrm{sec}$, and the resulting matrix needed to cover the required $17.5 \mathrm{sec}$ will be only $11 \times 11$, which is easily handled.

Processing speed. The operations of developing a data set that contains the real and the smoothed future data, performing the FFT, double-integrated acceleration in the frequency domain, and inverting the double-integrated acceleration (heave) back to the time domain must all be completed before the next real-time heave data point is needed. This time period depends on the sampling frequency of the digitized accelerometer data and will be between 50 and $150 \mathrm{msec}$. This time constraint determines the type of hardware and software that can be used for the system. Until recently, small processors were simply not fast enough to handle such computing requirements that require in excess of 100 floating point operations. Fortunately, digital signal-processing technology has recently evolved to the stage where its use will satisfy the processing requirements for the VMS-II.

\section{VMS-II hardware}

VMS-II utilizes the signals from standard off-the-shelf sensors for vertical acceleration, pitch, and roll. Signals from these sensors are input to a custom-designed circuit board that contains the analog low-pass filtering, digital-signal-processing (DSP) processor, required memory, and ancillary components. In the personal computer (PC) that is used to configure the system is a PC board with another DSP processor and a communications driver.

Input sensors. The three sensors used to measure the actual motions of the vessel are a Columbia Model SA-107B accelerometer and two Watson Model ADS-C131-1A clinometers. These three sensors are mounted in a portable box that is placed at a known location in the vessel. Inside the box the two clinometers are mounted at right angles to each other so that they will measure pitch and roll of the box. The box must be installed so that the clinometers will measure pitch and roll, and the accelerometer must be mounted as close to vertical as possible.

The box can be mounted in any location in the vessel; however, its location relative to the center of motion of the vessel must be accurately known. These known offsets can then be input to the computer to determine the true motion of the vessel. It is desired that the unit be placed as close to the fathometer or the center of motion of the vessel as practical and with the three sensors aligned with the respective vessel axes. 
Analog outputs from the three sensors are input to the printed circuit board (PCB) containing the analog and digital circuits required to compute heave. This circuit board is mounted in the box with the sensors and the power supplies.

Processing electronics. The processing electronics were originally designed as a system that contained two PCBs. One of the boards was to be installed in the sensor box, and the other was to be installed in the PC. Highspeed communications would be used to transfer data between the two boards so that the processing tasks could be shared. Actual development of the electronics showed that the entire processing could be performed on the PCB located in the box with the sensors. Thus, the board in the omputer is used simply as an input to start the system and as a means of logging data and assessing the operation of the system. This board can be utilized for additional processing, should modifications to the system require its use.

The main PCB is located in the sensor box together with the sensors and power supplies. This board contains the analog circuits that provide offset, gain, and filtering to the signals from the three sensors. Accelerometer output is scaled to 7.5 volts per $\mathrm{g}$ of acceleration. Clinometer signals are scaled to 0.100 volts $/ \mathrm{deg}$ and are offset to +7.5 volts. An additional analog channel is provided to enable proper offset, scaling, and filtering of the fathometer signal so that it has a phase shift identical to the motion-sensor signals. All analog channels are filtered using 8-pole switched cap modified low-pass filters. Provision is contained on the board for the input of a 2.0 -volt calibration signal to all analog channels.

The $\mathrm{PCB}$ also contains the digital processing electronics, which include the DSP processor, $64 \mathrm{~K}$ of 32-bit-word memory, and ancillary integrated circuits. Digital electronics also provide a long-term digital signal source that is used to eliminate the acceleration bias due to gravity and any long-term drift seen in the accelerometer signal.

VMS-II package. The VMS-II is contained in a junction box that contains connectors on the outside to bring in fathometer data, to send and receive signals from the PC, and to bring AC power to the power supplies. The VMSII is connected to the PC via a standard DB25 connector and is connected to $115-\mathrm{VAC}, 60-\mathrm{Hz}$ power through a standard power cord.

\section{VMS-II software}

The software for the VMS-II is written in two parts. An assembly language code is installed in the firmware of the system to perform communications and other board level operations while the main processing software is written in "C." A copy of the " $\mathrm{C}$ " processing code is contained in Appendix C of Carter et al. (in preparation). 


\section{Horizontal/Vertical Positioning System Utilizing GPS Satellite Constellation ${ }^{1}$}

Extensive hydrographic surveys are required to support the planning, engineering, design, and construction phases of the Corps' dredging functions. Hydrographic surveying and positioning are essential to prepare for and administer dredging projects (Geier, Loomis, and Kleusberg 1992).

\section{Present Surveying and Positioning Methodology}

Presently, horizontal positions of dredges and survey vessels are determined using systems that electronically measure multiple ranges or ranges and angles from previously established control points on shore. Most of these systems require the vessel to occupy a calibration point installed near the job site each work day to initialize the system. Furthermore, all of the systems require establishing a series of receiver/transmitters on control stations on shore. Maintaining these control stations, moving receiver/transmitters about, and performing the calibration process is extremely expensive and labor-intensive.

In addition, all dredging and survey operations are vertically referenced to the vessel performing the work. This reference is generally related to a tide or river gauge to reduce the depth readings to some datum, for instance, mean lower low water (mllw). This method assumes that water surface elevations at the gauge site accurately represent the surface elevations at the survey site. Actually, surface elevations can vary significantly between the gauge and the survey sites. Offshore tide gauges have been introduced as a means to produce mathematical models of the surface characteristics of a water body. With

\footnotetext{
1 Chapter 3 was extracted from Enge and Pfleiger (1992); Frodge, Remondi, and Lapucha (1994); Geier, Loomis, and Kleusberg (1992); Wells and Kleusberg (1992); and Wells, Wells, and Kleusberg (1992).
} 
GPS, vessel altitude is determined relative to the World Geodetic System-1984 (WGS-84) ellipsoid. Once an onshore tide gauge reading has been referenced to WGS-84 ellipsoidal elevation (by collocating a GPS receiver with the tide gauge), vessel depth gauge readings can be determined relative to mllw without the use of water-surface modeling.

In the late 1980s, Geier, Loomis, and Kleusberg (1992) conducted an analysis for a kinematic positioning system based on GPS. They believed a system requiring no onsite calibration and only one reference station would significantly increase the efficiency and productivity of the Corps hydrographic surveying. If such a system could simultaneously provide sufficient vertical accuracy, it could also serve as a means to rectify the tidal datum. For such a system to be accepted by the user community, it would have to provide a horizontal positioning accuracy of $\pm 2 \mathrm{~m}$ and a vertical accuracy of $\pm 0.1 \mathrm{~m}$. Geier, Loomis, and Kleusberg (1992) stated that even though a GPS kinematic positioning system may not require calibration to its reference station, it might have to be calibrated or aligned to the local project datum.

With deployment of GPS, the potential for a kinematic positioning system meeting those accuracy requirements materialized. Relative positions of a moving antenna meeting those accuracy requirements potentially were possible using GPS. Differential positioning using carrier-smoothed pseudoranges had demonstrated accuracies of a few meters. Differential kinematic surveys using carrier phase measurements had demonstrated accuracies of a few centimeters. However, experiments using the latter approach employed methods to initialize carrier lane ambiguity that were operationally inappropriate in the marine environment (occupation of known baselines, antenna swaps, static surveys, etc.). Additional development would be needed to recover full performance after loss of signal and cycle slips. Data transmission, handling, and reduction had not been fully developed for operational use in the late 1980s (Geier, Loomis, and Kleusberg 1992).

\section{GPS}

The NAVSTAR GPS is a passive, satellite-based, navigational system operated by the U.S. Department of Defense. GPS became fully operational in the mid-1990s. GPS consists of a complement of 24 satellites, control systems, and users. The nominal satellite altitude is slightly higher than $20,000 \mathrm{~km}$, resulting in an orbital period of 12 sidereal hours. The satellite constellation is oriented such that viewed from any place on earth, at least four satellites will be visible above the horizon at virtually all times (Wells and Kleusberg 1992).

The control system consists of monitoring stations on Diego Garcia, Ascension Island, Kwajalein, and Hawaii, and a master control station at the Consolidated Space Operations Center, Colorado Springs, CO. The purpose of the control center is to monitor the health of the satellites, determine their orbits and the behavior of their atomic clocks, and to transmit data to the satellites for rebroadcast to the users. These data contain ephemerides describing 
the satellite orbits, satellite clock-synchronization parameters, and a satellite health (usability) flag.

Each satellite transmits at two radio frequencies: $1,575.42 \mathrm{MHz}$ (L1) and 1,227.6 $\mathrm{MHz}(\mathrm{L} 2)$. Three kinds of modulations are imposed upon these carriers: (a) a 50-bit/sec modulation that contains the message (information about orbits, clocks, health, etc.); (b) a $10.23-\mathrm{MHz}$ pseudorandom noise code, the P-code, associated with the GPS precise positioning service (PPS); and (c) a 1.023-MHz pseudorandom noise code, the carrier/acquisition code (C/A code), associated with the GPS standard positioning service (SPS). Each GPS satellite has a different C/A code and a different segment of the P-code. Thus, the code identifies the satellite from which the signal came. GPS is designed so that the P-code (which is unclassified) can be replaced by a classified code, the Y-code, denying the PPS to nonqualified users (switching to the Y-code is referred to as "anti-spoofing"). In addition, the capability of adding intentional degradation to the SPS is designed into GPS (this is referred to as "selective availability").

GPS receivers track these signal components from several GPS satellites simultaneously to obtain enough information to determine their own position. The satellite orbital information in the message from each satellite is used to compute the position of that satellite. Either the C/A code or the P-code can be used to measure the distances between the receiver and each satellite. Each distance measurement implies the receiver is somewhere on the surface of a sphere centered at the satellite with radius equal to the distance measurement. Simultaneous measurements to several different satellites yield several such spherical "surfaces of position." The 3-D $(x, y, z)$ position of the receiver is found by determining the point at which these spheres intersect.

The problem of synchronizing receiver and satellite clocks is handled in the following manner. The standard method of solving this problem is to assume that the clocks in all GPS satellites are synchronized (by data from the control center) and to treat the offset of the receiver clock from these satellite clocks as a fourth unknown parameter to be solved together with three coordinates of position. Solution of these four parameters requires simultaneous tracking of at least four satellites.

\section{Feasibility of decimeter-level GPS}

In 1989 Wells and Kleusberg (1992) concluded that as far as the feasibility of decimeter-level positioning was concerned, the most important practical aspect was the possible use of the carrier to provide distance measurements, which would be far more precise than the distances measured by using the codes. Range measurements could be made with a precision of approximately 1 percent of the wavelength of the signal being used. The GPS L1 carrier (at about $1.6 \mathrm{GHz}$ ) has a wavelength of about $20 \mathrm{~cm}$, implying a ranging precision of $2 \mathrm{~mm}$. In contrast, the P-code (with chipping rate of about $10 \mathrm{MHz}$ ) has a chip length of $30 \mathrm{~m}$, implying a ranging precision of about $30 \mathrm{~cm}$, and the 
C/A code (with chipping rate of about $1 \mathrm{MHz}$ ) has a chip length of about $300 \mathrm{~m}$, implying a ranging precision of about $3 \mathrm{~m}$.

However, the higher precision of carrier measurement would not come without cost. P-code ranges were unambiguous. C/A code ranges were ambiguous with a modulus of about $300 \mathrm{~km}$ (C/A code ranges included an unknown multiple of $300 \mathrm{~km}$ ), which would be relatively easy to resolve. However, $\mathrm{L} 1$ carrier ranges were ambiguous with a modulus of about $20 \mathrm{~cm}$, which would be much more difficult to resolve; hence, it was important that the carrier be tracked continuously without cycle slip (or if cyclic slips occurred, that they be correctable). Data-link alternatives were investigated by Enge and Pflieger (1992).

In the opinion of Wells and Kleusberg (1992) in 1989, the feasibility of decimeter accuracies for GPS depended to a large extent on the feasibility of being able to realize the high precision of ranges derived from carrier beat phase measurements by reliably resolving the carrier ambiguity and either preventing or reliably correcting carrier cycle slips.

\section{Absolute versus differential GPS positioning}

Absolute GPS. GPS was designed to provide a point-positioning capability. In this mode, the coordinates of a point are determined using signals received by a GPS receiver simultaneously from several GPS satellites. This is called absolute positioning and is the method designed to meet the primary GPS military missions, as well as many nonmilitary applications.

As shown in Figure 2, there are three GPS absolute-positioning techniques, each with different levels of accuracy. Civilians will have access to the SPS positioning service, using the C/A code for range measurements. This is a little less than half as accurate as the precise PPS positioning service, available to U.S. and NATO military users, as long as the intentional degradation known as selective availability has not been applied, in which case the SPS becomes about eight times less accurate than the PPS.

Differential GPS. The ultimate limitation on GPS positioning accuracy is not the accuracy with which GPS range measurements can be made, but the effects of biases and errors on these measurements. Many of these biases have a high spatial correlation. Errors in position determination resulting from these biases will also have a high spatial correlation. Since the errors in point positioning at each of two receivers will have almost the same magnitude and orientation, the error in the position of one relative to the other will be much smaller. This is the basis of differential GPS positioning, also called relative GPS positioning. More than one receiver must be used, and the coordinates of at least one of the receivers must be known.

Figure 2 also shows the comparison of four differential GPS positioning methods. The method labelled differential code does not make any use of the 


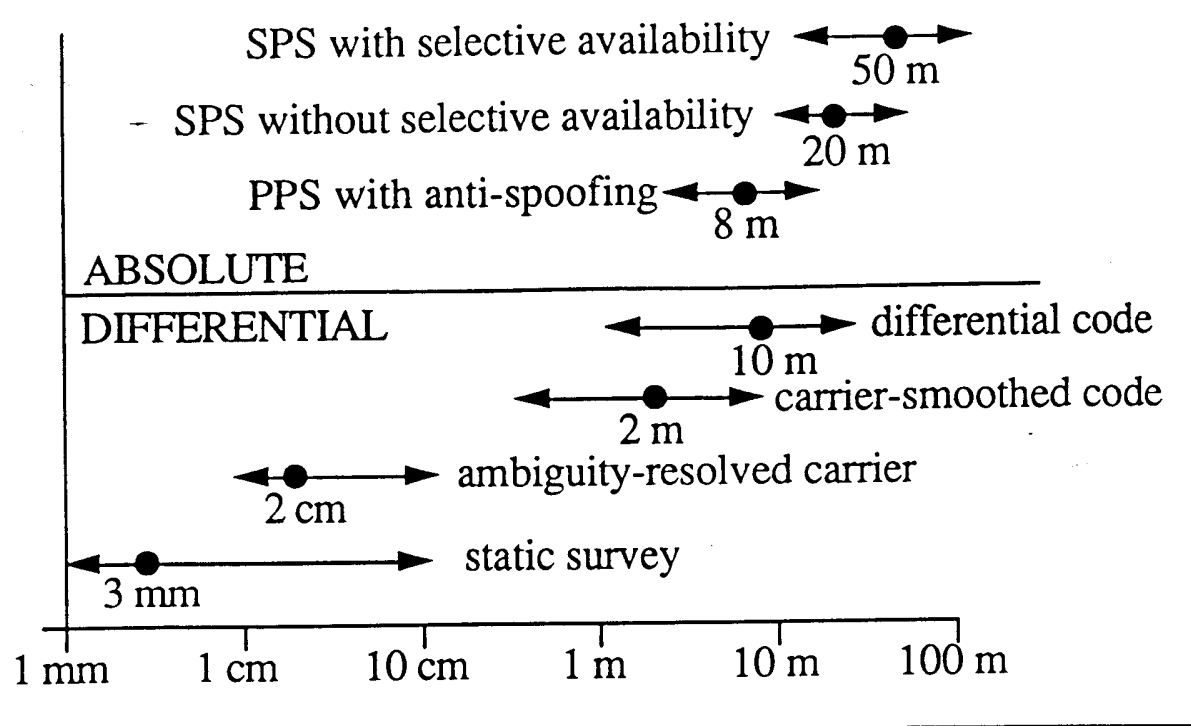

Figure 2. Absolute and differential GPS. (Arrows show range of accuracies to be expected. Dots and numbers represent typical accuracies within that range) (from Wells and Kleusberg (1992))

carrier at all. It does permit PPS users to improve their accuracy slightly, and SPS users with selective availability can achieve accuracies nearly comparable to PPS users.

The method labelled carrier-smoothed code combines the differentialpositioning capabilities of the GPS code with the differential vehicle displacement sensing capabilities of the carrier. This method, successfully demonstrated in several field trials by 1989 , does not require that carrier ambiguities be resolved. The effect of carrier cycle slips is transitory.

The method labelled ambiguity-resolved carrier realizes the full precision of carrier measurements by resolving the carrier ambiguity and preventing or reliably correcting cycle slips. (The resolution of carrier ambiguities on the fly was the technique used in developing the Corps of Engineers real-time GPS positioning system by the Dredging Research Program.)

The method labelled static survey is included for comparison only, since it does not have implications for kinematic applications. Static surveys benefit, in comparison to kinematic surveys, from being able to use GPS range data collected over some period of time, which will reduce the effect of error sources that can be considered random over the observation period.

GPS is a 3-D positioning system. However, determination of horizontal coordinates and determination of height have different characteristics. For vessels operating on the sea surface, horizontal coordinate determination is the 
primary tool for navigation and track control, while height determination monitors sea level.

\section{Corps of Engineers Real-Time, On-the-Fly Differential GPS System}

Since 1988, the DRP has been developing a GPS carrier phase-based positioning system for hydrographic surveying and dredging (Figure 3) (Frodge, Redmondi, and Lapucha 1994). This system provides real-time 3-D positions with horizontal and vertical accuracies of less than $10 \mathrm{~cm}$ over ranges up to $20 \mathrm{~km}$ from a single known reference station. The system does not require static initialization. The project passed from concept development through feasibility studies, system analysis, resolution of carrier ambiguities on the fly (OTF), to final system integration.

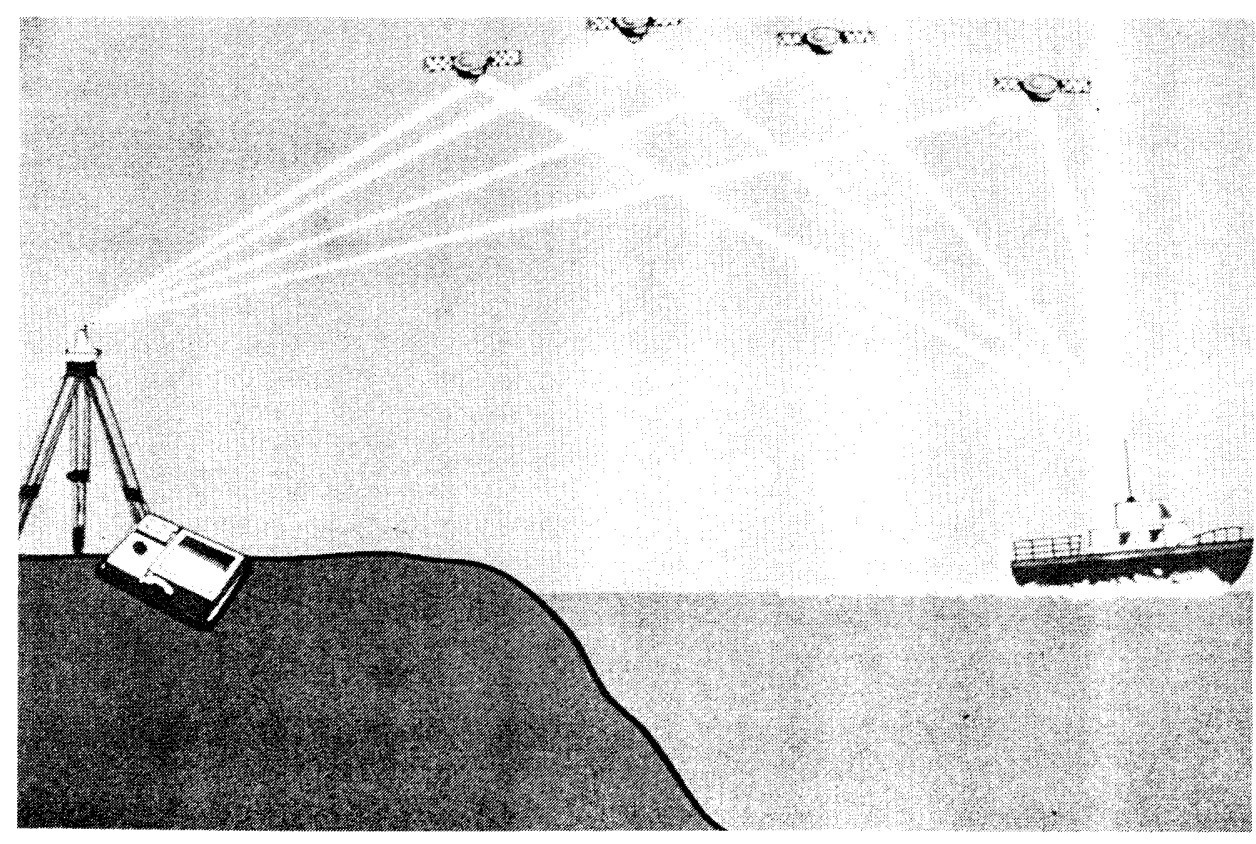

Figure 3. Real-time OTF GPS

Real-time testing of the system began in March 1993, and public demonstrations began in October 1993. Testing of the system has been performed under various conditions to evaluate the limits of OTF ambiguity resolution for precisely positioning moving platforms. Tests have shown that this system is

- capable of 1- to 3-cm accuracy in all three dimensions. Using a positioning system that is accepted as definitively accurate can decrease disputes over costs that arise from disagreements on the actual amount of dredged material removed. Additional savings are realized on a per-job basis because of the requirement for fewer personnel and decreased number of shore stations (i.e., 
only a single shore station of known coordinates is needed, and daily calibration is not_necessary).

\section{OTF system}

The real-time OTF prototype delivers high-precision kinematic positioning accurate to about $2 \mathrm{~cm}$ at the antenna phase center, while simultaneously providing a separate output for meter-level differential GPS (DGPS) for navigation purposes. A block diagram of the system is shown in Figure 4. The system performs OTF carrier phase ambiguity resolution.

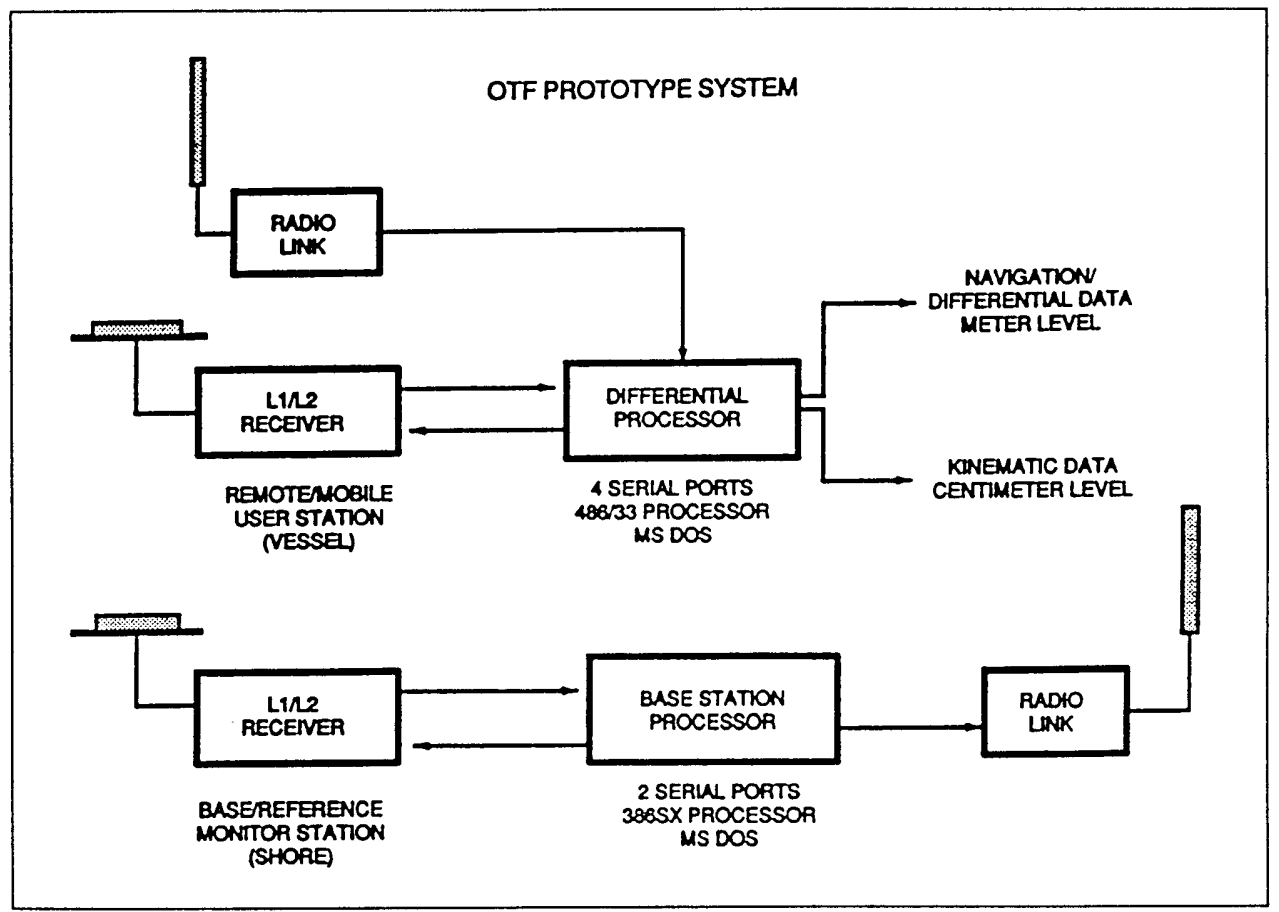

Figure 4. Block diagram of OTF prototype system

As a design constraint, the OTF system was developed using only equipment that could be purchased off the shelf. The OTF software is the heart of the system and was the focus of much of the development effort. The software was designed to require minimum operator attention and has several built-in quality-control procedures to ensure that high performance and reliability of the system are maintained.

The system consists of setups at the reference (monitor) and remote (user) stations and a data link, shown schematically in Figure 4. Dual-frequency (L1/L2) GPS receivers are required at both the reference and remote stations. Shipping the raw data from the reference station allows a single 386SX PC to carry out the reference station functions. These functions include setting the GPS receiver to output the required data, translating those data to the desired 
format, and transferring the formatted data to the data link for transmission. Additionally, the station package is capable of recording data at the operator's request. Although the prototype was developed and built using 486 computers and Trimble 4000 SSE receivers, other platforms and receiver types are being interfaced to use the OTF software.

High-precision kinematic OTF (KOTF) mode positioning is available from the system once integer ambiguities are resolved by the software. As long as the system remains in the KOTF mode, real-time subdecimeter positioning in three dimensions is available at the mobile (user) site. To remain in this KOTF mode requires both reference-station data and a maintenance of lock on at least four satellites. If that number drops to below four, the ambiguities will again be resolved after the system reacquires lock on a sufficient number of satellites. The software is "smart," and will automatically detect the need to reinitialize. The software will also trigger reinitialization if quality factors based upon residuals fail to meet certain predefined limits. Note that the system is still capable of meter-level DGPS navigation even if loss of lock occurs; the system will provide this function for a limited time even without data from the reference station.

The system uses L1/L2 carrier phase and C/A code ranges for ambiguity resolution. The system has been designed not to rely on the continuity of L2 carrier phase, since only the fractional phase part of the L2 carrier measurements is used. After ambiguities are resolved, only the L1 carrier ranges are required to maintain the high-precision KOTF positioning. Note that the Interface Control Document 200 (ICD 200) parameters are required by the system not only at startup of the software, but whenever the GPS satellite constellation changes or an ephemeris update occurs. Figure 5 depicts the general flow of required GPS data. The meter-level DGPS process uses C/A code and L1 carrier ranges.

The current prototype was developed on the premise that all required raw GPS observations (GPS time lag, L1/L2 carrier phase, C/A code) are transmitted from the reference monitor station and that the actual computations necessary for KOTF and DGPS take place at the remote user station. The KOTF process requires time-matched reference and remote-station data. In the code differential process, extrapolated reference-station differential corrections are applied to the current remote-station observations, as is done in standard DGPS systems. The difference is, however, that these corrections with their rates are generated at the remote site from the raw data that were received from the reference station data.

The system can be interfaced with any other system requiring this level of accuracy in positioning, using an interface string. The string was designed to be as close as possible to the existing National Maritime Electronics Association GPS string formats (NMEA 0/83). The system works in a robust and reliable manner out to the design-goal range of $20 \mathrm{~km}$ in real-time, although the range limit is greater. 


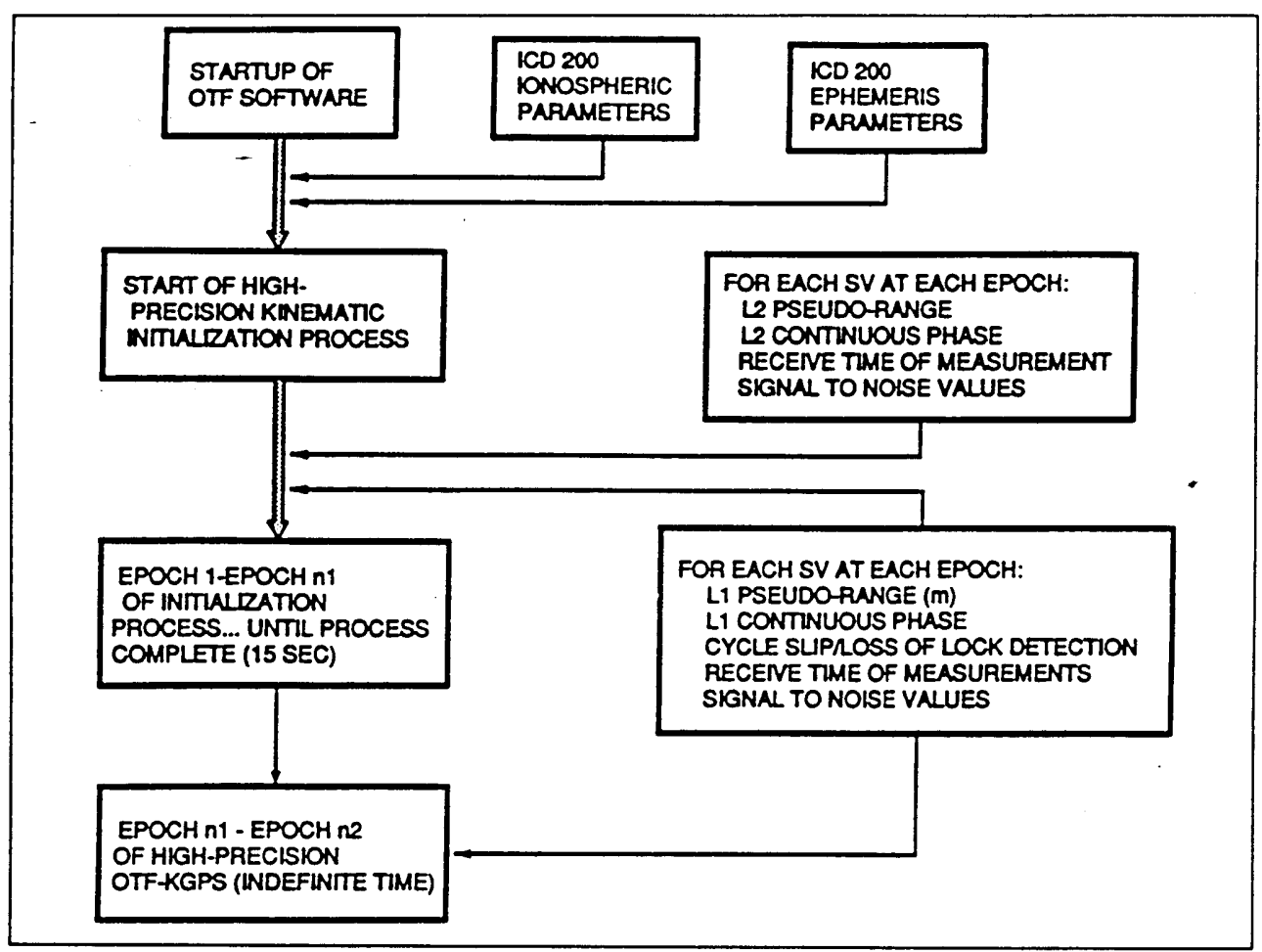

Figure 5. Schematic of information flow required by OTF system

\section{Real-tlme testing}

Real-time testing was broken into stages that progressed from static-baseline tests, to land-mobile tests, and finally to tests in an operational environment aboard a survey vessel. Static tests determined that the system performed well over the full variation of GPS visibility and conditions. Typically, positions were obtained 98 percent of the time. The remaining 2 percent of the time, integers could not be established because of poor-satellite constellations (containing several low-elevation satellites) or not enough satellites.

The usual setup for any land-mobile test or demonstration entailed setting up a truck or cart as the mobile remote user and then navigating the user system to positions previously established using static GPS methods. Horizontal positions checked within 1 to $2 \mathrm{~cm}$, and the vertical positions were within 1 to $3 \mathrm{~cm}$. The system was also closely observed while enroute between stations, with driving speeds varying between 8 and $40 \mathrm{~km} / \mathrm{hr}$. Its performance was found to be very satisfactory.

The next step was to move the system onto a survey vessel. Initial tests had the OTF reference station installed atop an office building, and the remoteuser equipment was installed on the survey vessel. The tests compared the real-time vertical positions obtained over time using the OTF system with tidegauge readings to determine vertical accuracy relative to tidal movement of the 
vessel. For these tests, the vessel was tied to the dock for a full tidal swing of $8 \mathrm{hr}$. Results varied from 1 to $2 \mathrm{~cm}$ in the vertical direction.

Next the system was field-tested aboard survey vessels in two different demonstrations along the Atlantic Coast and the Pacific Coast. Here the vessels ran several longitudinal and cross-sectional lines that took the vessels underneath bridges on the way to the survey areas and again on the return trips. The worst case experienced was that the OTF system lost lock and did not reinitialize until within the fourth pass (a pass is $15 \mathrm{sec}$ ), less than $1 \mathrm{~min}$. The typical case was that one 15 -sec pass was required, and the system initialized in the forward manner on that first pass. There were several occasions when the vessel passed under the bridge and the system maintained uninterrupted operation at both the meter and subdecimeter levels.

Additional tests were conducted to demonstrate the OTF system onboard a dredge in open ocean waters as well as in a busy harbor area. In a demonstration onboard the Corps hopper dredge Essayons, the system was operated in ocean waters that provided 2- to 4.5-m swells. Also, since the Essayons' work was in shipping lanes, vessel traffic was evident. In another test onboard the Essayons, the system encountered a realistic operational environment that determined the operational limits and constraints of the OTF system.

\section{Conclusions}

Centimeter-level accuracy in real-time is a reality. Tests have demonstrated that this technology will have a great impact on both surveying and navigation. This particular system is robust, reliable, and easy to use and has surpassed its original design-goal specifications. The tests have shown that real-time tide corrections using OTF are possible; this is very important for the dredging industry. The system has far exceeded the original design specifications and can be used today as a reliable working system for applications that require real-time centimeter horizontal positioning. It is also a valuable engineering tool for those operations for which postprocessed data will suffice. In reality, it has been demonstrated that real-time OTF is as easy to provide as DGPS within the current range limitations of $20 \mathrm{~km}$ (Frodge, Remondi, and Lapucha 1994). 


\section{Production-Meter Technology ${ }^{1}$}

A dredge production-meter system consists of a density gauge, a velocity meter (flowmeter), an output display that is easy to visualize and understand, and a means of recording, storing, and totaling the data. The velocity meter and the density gauge together estimate dredge production. The accuracy of this estimate is a function of the accuracy of the individual meters. Production-meter information can be used to increase dredge production and improve overall dredging efficiency. The data also can be used to improve understanding of the dredging process and the effect of specific parameters on an individual dredge.

There are several types of velocity meters (i.e., electromagnetic, doppler acoustic, and differential pressure), each with its own level of accuracy. The same is true for density-measuring devices. Calibration is performed at the factory by manufacturers' representatives using an average type slurry. As the slurry type changes under real dredging conditions, the output information from the sensors will vary. Under identical conditions, a production calculation using doppler velocity meter and nuclear density gauge values may be very different from calculations made using a bend velocity meter and pressure transducer specific gravity $U$ loop values.

\section{Dredge Production-Meter Use}

A study was conducted by the DRP to identify instruments being used by operating dredging companies to measure and monitor dredge production. The study consisted of a survey of production-meter use, supplemented by information from instrument manufacturers and by visits to manufacturing plants and several working dredges. The velocity meters and density meters identified in the survey were later comparison tested under similar conditions to determine instrument accuracy and reliability over a range of operating values.

1 Chapter 4 was extracted from Pankow (1989, 1990, 1991) and Scott (1992). 


\section{User survey}

Survey questionnaires were sent to 472 foreign and 197 domestic dredging organizations (including Corps District offices) (Pankow 1990). Of the 56 organizations that responded, 32 organizations (14 foreign and 18 U.S.) used some type of production-monitoring instrumentation on 72 dredges. Also reporting were 24 organizations ( 8 foreign and 16 U.S.) that at the time of the survey had no production-measuring instrumentation on 51 dredges. In the United States, 32 dredges were reported to be using some type of productionmonitoring instrumentation (14 hopper dredges, 16 cutterhead pipeline dredges, 1 sidecaster dredge, and 1 dustpan pipeline dredge).

The pipeline dredges ranged in size of discharge-pipe diameter from 8 to 45 in. Most were in the 8- to 16-in. and 24- to 36-in. range. The size of the hopper dredges, as measured by the capacity of the hopper bin, ranged from 500 to $16,000 \mathrm{cu}$ yd, with the majority being in the 2,000 - to 6,000 -cu-yd size range.

\section{Instrumentation used}

The most frequently reported combination of velocity and density meters was the magnetic velocity meter and nuclear density gauge: 36 of the 52 dredges with complete production-meter systems used this combination (21 hopper, 15 pipeline). Ten dredges used a doppler velocity meter with a nuclear density gauge ( 6 hopper, 4 pipeline). Eleven of 13 dredges that used only velocity meters were pipeline dredges. They used eight doppler, two magnetic, and one pressure gauge to monitor slurry velocity. The velocity meters used on the two hopper dredges were of the pressure-gauge type. The single dredge that reported using only a density gauge was a cutterhead dredge that used a displacement gauge to determine slurry density.

\section{Output displays}

The cross-point display for production-meter systems was specified as being used on one-third of the dredges. This single display provides three pieces of information to the user. One pointer indicates slurry velocity, another pointer indicates slurry density, and the intersection of the two pointers indicates the dredge's production rate. Another one-third indicated use of analog displays other than cross point, and the remaining one-third used a variety of digital and graphic displays.

\section{Uses of production-meter Information}

All dredge operators who had production-meter information available reported using the information to help increase the density of the pumped slurry and thus to increase production. One dredge operator used the 
production meter as a training aid for new levermen, while another used it to evaluate and compare leverman efficiencies. One sidecaster dredge operator used the production meter to optimize production by varying the vessel's operating parameters such as vessel speed through the water, pump speed, and digging depth. Some operators whose dredges had only velocity meters monitored the slurry velocity to maintain a certain critical velocity for their pipeline. This was stressed as especially important when long pipelines were in use.

\section{Laboratory Tests}

Production (velocity and density) meters identified in the worldwide survey as being used onboard operating dredges were laboratory tested to evaluate instrument performance under controlled conditions of slurry type, concentration, flow, and pipe orientation (Pankow 1989). Tests were conducted at Georgia Iron Works (GIW), Inc., a pump design and fabrication company that operates a research facility to test and evaluate their pumps. Part of the research facility includes a closed test loop in which slurry flow and concentrations can be monitored, controlled, and measured. This loop was used to evaluate the performance of several velocity and density meters for a number of conditions.

GIW facility meters that were used as controls were calibrated according to procedures established at GIW, which uses an American Society for Testing and Materials standard orifice plate. All test meters were installed and calibrated according to manufacturers' procedures by the manufacturers' factory technicians. Once the tests were started, no adjustments were made to any of the meters. The meters tested included: (a) doppler velocity meters (Leeds \& Northrup, Texas Nuclear, Polysonics); (b) magnetic velocity meters (Brooks, Rosemount); and (c) nuclear density meters (Texas Nuclear, Kay-Ray).

\section{Test slurrles and methods}

A series of tests were run with four different grain-size materials each at three different concentrations $(20,30$, and 40 percent concentration by weight) through a flow range from 0 to $4,000 \mathrm{gpm}(0-26 \mathrm{fps})$. The test instruments were mounted on a U-shaped section of pipe that could be raised $90 \mathrm{deg}$ from a horizontal to a vertical orientation. The diameter of the pipe used for these tests was 8 in. Data for the control and test meters were taken at 12 to 15 points along the flow range with the pipe oriented in either the vertical or the horizontal position. The location of the test meters on this special section of pipe is illustrated in Figure 6, along with the location of a glass observation section. The control velocity and density meters were located approximately $330 \mathrm{ft}$ upstream from the test instruments. Table 1 lists the test conditions. Before each new material was tested, data were collected through a range of velocities with only water in the test loop. 


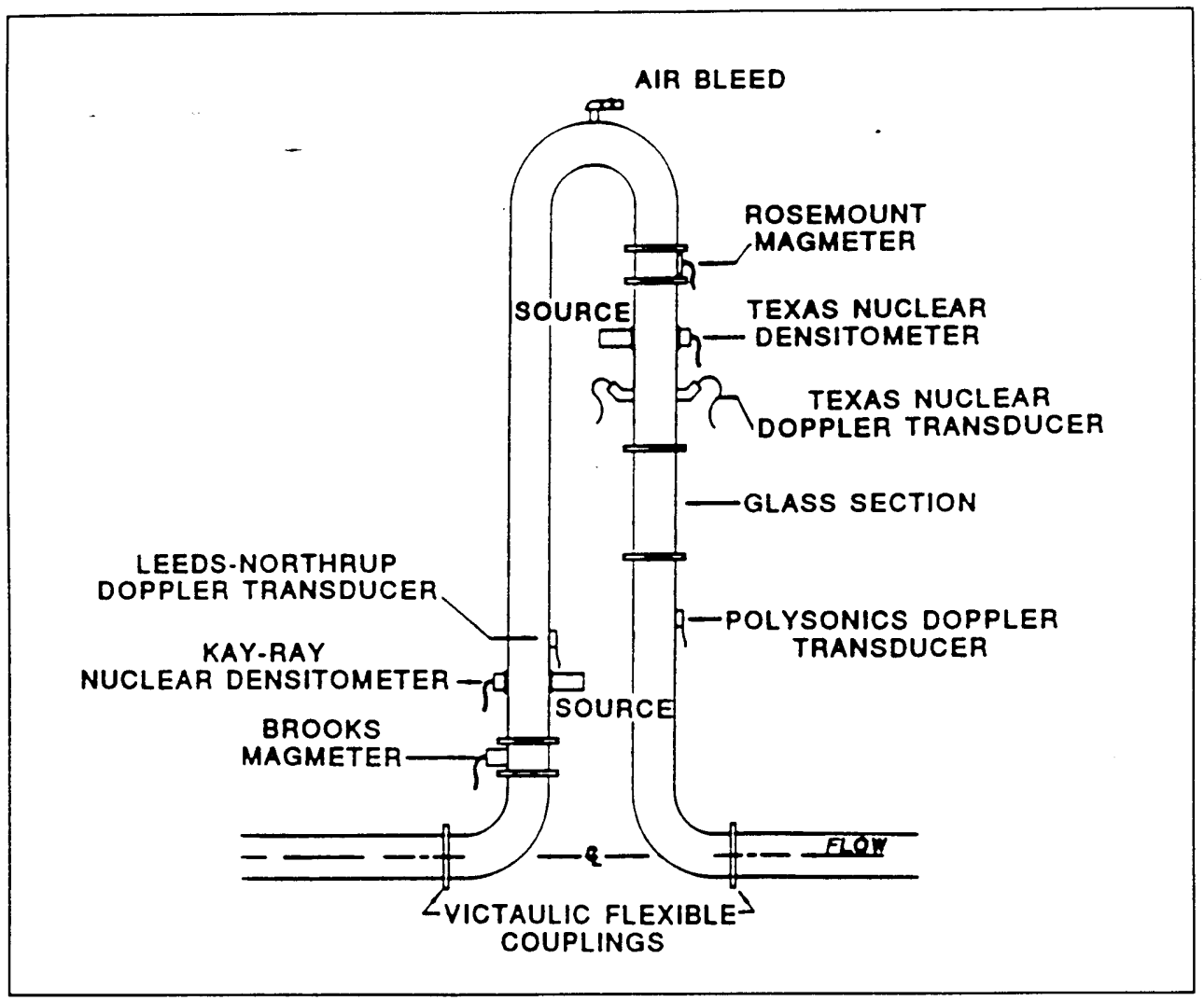

Figure 6. GIW instrumentation loop for testing dredge production meters

\begin{tabular}{|c|c|}
\hline \multicolumn{2}{|c|}{$\begin{array}{l}\text { Table } 1 \\
\text { Production-Meter Laboratory Test } \\
\text { Conditions }\end{array}$} \\
\hline \multicolumn{2}{|c|}{ Materlal Types } \\
\hline Gravel & $D_{50}=16-19 \mathrm{~mm}$ \\
\hline Plaster sand & $\mathrm{D}_{30}=0.70 \mathrm{~mm}$ \\
\hline Foundry sand & $D_{50}=0.30 \mathrm{~mm}$ \\
\hline Sand washings & $D_{50}=0.06 \mathrm{~mm}$ \\
\hline \multicolumn{2}{|c|}{ Slurry Velocity Range } \\
\hline \multicolumn{2}{|c|}{$0-26 \mathrm{fps}(0-4,000 \mathrm{gpm})$} \\
\hline \multicolumn{2}{|c|}{ Slurry Concentrations } \\
\hline \multicolumn{2}{|c|}{ Specific gravity $(\mathrm{SG})=1.1-1.3$} \\
\hline \multicolumn{2}{|c|}{ Concentration by weight $\left(C_{w}\right)=15-40$ percent } \\
\hline \multicolumn{2}{|c|}{ Test Loop Orientation } \\
\hline \multicolumn{2}{|l|}{ Vertical } \\
\hline \multicolumn{2}{|l|}{ Horizontal } \\
\hline
\end{tabular}

\section{Test results}

Table 2 shows the largest percent difference values from the control velocity and density meters for the range of concentrations and material types tested in both the vertical (90-deg) and horizontal (0-deg) pipe orientations. Concentrations by weight ranged from 15 to 40 percent for four different material types: (a) plaster sand; (b) foundry sand; (c) sand washings; and (d) gravel. With sand slurries, the nuclear density meters had values within 1 percent of each other; for gravel this

increased to almost 5 percent. The magnetic velocity meter values were within 4.7 percent of each other for sand slurries and 5.7 percent for gravel. Both 


\begin{tabular}{|c|c|c|c|c|c|c|c|c|}
\hline \multicolumn{9}{|c|}{$\begin{array}{l}\text { Table } 2 \\
\text { Largest Percent Difference from Control for Slurry } \\
\text { Concentratlons }\end{array}$} \\
\hline \multirow[b]{3}{*}{ Manufacturer } & \multicolumn{2}{|c|}{ Plaster Sand } & \multicolumn{2}{|c|}{ Foundry Sand } & \multicolumn{2}{|c|}{$\begin{array}{c}\text { Sand } \\
\text { Washings }\end{array}$} & \multicolumn{2}{|c|}{ Gravel } \\
\hline & \multicolumn{8}{|c|}{ Pipe Orientation, deg } \\
\hline & 90 & 0 & 90 & 0 & 90 & 0 & 90 & 0 \\
\hline \multicolumn{9}{|c|}{ Nuclear Density Gauge } \\
\hline Texas Nuclear & -0.1 & -0.7 & 0.0 & 2.2 & 0.5 & -0.1 & 4.0 & 5.0 \\
\hline Kay-Ray & -0.1 & -2.0 & -1.0 & 2.2 & 0.7 & 0.5 & -0.7 & 7.5 \\
\hline \multicolumn{9}{|c|}{ Magnetic Velocity Meter } \\
\hline Brooks & -0.1 & 2.5 & 0.5 & -3.7 & -2.1 & 1.0 & 0.0 & 5.0 \\
\hline Rosemount & -1.0 & 5.0 & -1.5 & 1.0 & 3.5 & -1.5 & -2.0 & -0.7 \\
\hline \multicolumn{9}{|c|}{ Doppler Velocity Meter } \\
\hline Leeds \& Northrup & -7.0 & -6.0 & 0.0 & 7.0 & -5.0 & -5.0 & 20.0 & 17.0 \\
\hline Texas Nuclear & 20.0 & 30.0 & 25.0 & 20.0 & 15.0 & 15.0 & 15.0 & 50.0 \\
\hline Polysonics & -15.0 & -15.0 & -15.0 & -7.0 & -10.0 & -15.0 & -12.0 & -7.5 \\
\hline
\end{tabular}

performed better when mounted on the vertically oriented pipe section. The data for the doppler velocity meters show similar trends and, although each meter is fairly self-consistent, there are distinct differences among the three doppler velocity-meter test values. The doppler velocity meters show greater differences from the control velocity meter than did the magnetic velocity meters in all cases.

The meters were influenced by material type in that the gravel data presented the greatest percent difference for both the velocity and density meters. Slurry flow had no significant effect on the magnetic velocity meters or the nuclear density meters, but did affect the doppler velocity meter values. The differences between the control velocity-meter values and the test doppler velocity-meter values increased with increasing slurry flow. At a control-meter flow of $1,000 \mathrm{gpm}(6.5 \mathrm{fps})$, the doppler velocity-meter values were from 0.5 to 28 percent higher than the control velocity meter, and at a flow of $4,000 \mathrm{gpm}$ ( $25.6 \mathrm{fps}$ ), values were from 22 percent lower to 16 percent higher. This trend was observed with the doppler instruments when the pipe was in either the vertical or the horizontal orientation. At high flows, even without sediment, the doppler velocity meters tended to record lower values than the control velocity meter.

Slurry concentration appeared to have only a minor influence on the meter values in all but one condition. In general, the percent difference increased 
slightly with the increase in slurry concentrations. However, at high slurry concentration, low flow, and horizontal pipe orientation, material settled on the bottom of the pipe and moved as a sliding bed with higher velocity less-dense fluid moving above the bed. This condition is conducive to dune formation and movement, which was observed. With this condition present, erroneous or erratic values could be recorded.

This laboratory study emphasized that caution should be used in the selection of a production meter, especially the velocity-meter component. Ideally a magnetic velocity meter should be used, giving careful consideration to factors such as accuracy, initial cost, and maintenance requirements. The easiest velocity meter to install and the least expensive to purchase is the doppler type. However, this type of meter showed more variation in the data and differed most from the control velocity meter. The data spread among the three doppler velocity meters was much greater than the data spread between the two magnetic velocity meters.

The nuclear density meter is the only readily available densitometer used on contemporary dredges. It is reliable, accurate, and safe to use. However, it does employ a radioactive source and therefore a Nuclear Regulatory Commission (NRC) license is required. Many dredge operators prefer not to use this type of meter because of the licensing and training required.

This laboratory study indicated that, for determining dredge production, the most reliable instruments for measuring slurry flow and density are the magnetic velocity meter and the nuclear density meter, respectively (Pankow 1989). Their accuracy is enhanced when they are mounted on a vertical pipe section.

\section{Evaluation on Dustpan Dredge Jadwin}

To gain field experience for planning, installing, and operating a production-meter system, such a system was installed on the dustpan dredge Jadwin by DRP researchers (Pankow 1991). Since this was to be a temporary installation, the decision was made to use a doppler velocity meter, which, along with the nuclear density meter, is clamped to the exterior of the discharge pipe. The use of a magnetic velocity meter requires the installation of a specially lined pipe section containing the velocity sensors. These are custom manufactured and are not usually available for temporary use. The acoustic doppler velocity meter is frequently used on pipeline dredges, and its use on the Jadwin provided an opportunity to observe its performance.

\section{The Jadwin}

The Jadwin is a dustpan dredge operated by the U.S. Army Engineer District, Vicksburg, on the Mississippi River. The dustpan head is fitted with numerous water jets to loosen and fluidize the sediment being dredged. The 
slurry is discharged against a baffle plate at the end of a 1,000-ft-long floating discharge line. The production meter was used to evaluate the effect of pump speed and water-jet pressure on dredge production.

\section{Production-meter Installation}

A production-meter system that consisted of a Berthold nuclear density meter, a Berthold signal processor and production calculation unit, a singlesensor Polysonics doppler velocity meter, a vertical bar output display, and a dot matrix printer was leased for installation aboard the Jadwin in August 1989. The installation took place while the Jadwin was active in dredging in the Mississippi River. The installation did not interfere with the dredging process since all sensors were mounted on the outside of the discharge pipe.

\section{Calibration}

The velocity meter was factory-calibrated on a pipe section of the same material and size as the Jadwin for a velocity range of 0 to $26 \mathrm{fps}$ with a 4- to 20-MA output signal. Only one measuring point was necessary for start-up of the density meter, but the system has the capability to accept additional calibration values for increased accuracy. A density meter is best calibrated by passing two materials of known density through the pipe, ideally the carrier fluid and the dredged slurry. On the Jadwin it would be difficult and dangerous to attempt to capture a sample from the end of the discharge pipe as it hits the baffle plate. It also would not be truly representative of the average material passing through the pipe since heavier material moves along the bottom of the pipe while the lighter material moves above it. Therefore, the density meter was calibrated with the river-water carrier fluid. With the dredge pumping river water, an automatic averaging program calculated the average pulses detected. This was equated to a measured volume and weight of the same water sample.

Another required input value is the in-situ density of the bottom material. For the sandy sediment to be dredged by the Jadwin, a simple field expedient procedure was used to provide a good approximation of in-situ density. This procedure should only be used with predominantly sandy material containing very little mud or silt.

\section{Dredging parameter test}

Dredge-pump speed. The production-meter information was used to better understand the effects of dredge-pump speed and water-jet pressure on the Jadwin's dredging ability. With the water-jet pump operating in the normal mode of $70 \mathrm{psi}$ at $1,000 \mathrm{rpm}$, the dredge-pump speed was varied from 150 to $190 \mathrm{rpm}$ and production-meter data of slurry density and velocity were recorded. The data show that slurry velocity is initially directly related to 
dredge-pump speed, but the velocity reaches a maximum and then remains constant, as shown in Table 3 . The slight decrease in slurry density at $170 \mathrm{rpm}$ is inconsistent, and even though the slurry velocity increased (from the 160 -rpm value), a decrease in production rate was observed. These data illustrate that density is the more important factor in the production equation.

\begin{tabular}{|l|l|l|l||}
\hline \hline $\begin{array}{l}\text { Table 3 } \\
\text { Influence of Dredge-Pump Speed on Production }\end{array}$ \\
\hline \hline $\begin{array}{l}\text { Pump Speed } \\
\text { rpm }\end{array}$ & $\begin{array}{l}\text { Density } \\
\text { (specific gravity) }\end{array}$ & $\begin{array}{l}\text { Slurry Velocity } \\
\text { fps }\end{array}$ & $\begin{array}{l}\text { Production Rate } \\
\text { cu yd per hr }\end{array}$ \\
\hline \hline 150 & 1.15 & 17.5 & 2,400 \\
\hline 160 & 1.18 & 17.7 & 2,900 \\
\hline 170 & 1.16 & 18.7 & 2,700 \\
\hline 180 & 1.22 & 21.0 & 4,300 \\
\hline 190 & 1.20 & 21.0 & 3,727 \\
\hline
\end{tabular}

Water-jet pressure. To evaluate the effect of water-jet pressure on dustpan dredging, the water-jet pump pressure and speed were varied from 0 to 70 psi with the dredge-pump speed held constant at $190 \mathrm{rpm}$. The data of Table 4 show that a water-jet pump pressure between 16 and 38 psi (500 to $750 \mathrm{rpm}$ ) is needed before a pipeline slurry density above 1.1 specific gravity can be obtained. There appears to be a minimum water-jet pump pressure necessary to fluidize and expand the sediment for creating a sediment environment for the dustpan head to dredge.

\begin{tabular}{||l|l|l|l||}
\hline \hline \multicolumn{4}{|l||}{$\begin{array}{l}\text { Table 4 } \\
\text { Influence of Water-Jet Pump Pressure on Production }\end{array}$} \\
\hline \hline $\begin{array}{l}\text { Pressure } \\
\text { psi }\end{array}$ & $\begin{array}{l}\text { Density } \\
\text { (specific gravity) }\end{array}$ & $\begin{array}{l}\text { Slurry Velocity } \\
\text { fps }\end{array}$ & $\begin{array}{l}\text { Production Rate } \\
\text { cu yd per hr }\end{array}$ \\
\hline \hline 0 & 1.05 & 23.1 & 1,240 \\
\hline 6 & 1.09 & 22.6 & 1,945 \\
\hline 16 & 1.09 & 22.3 & 1,867 \\
\hline 38 & 1.15 & 21.7 & 2,930 \\
\hline 50 & 1.17 & 21.4 & 3,274 \\
\hline 70 & 1.19 & 21.2 & 3,728 \\
\hline
\end{tabular}




\section{Recommendations from the Jadwin tests}

- The experience with the production-meter system on the Jadwin produced several recommendations for the planning, purchasing, installing, and functioning phases of similar operations. Some areas of consideration are:

a. Include the users of the equipment and the data in the entire planning process. Each user may have different needs, and all needs should be addressed.

b. Decide on the units of measurement for the output gauges and identify the realistic ranges of readings that will be obtained.

c. Be sure the contractor understands the dredging operator's needs and provides an explanation of all equations used to calculate dredge production.

d. Have the output readout display calibrated so the normal operating range is about midscale and specify a scale of values that would detect changes of 2 to 5 percent.

$e$. Keep the output display uncomplicated so the primary user can easily observe and understand the readings.

f. Decide where the output gauge(s) will be located; identify the acceptable parameters of instrument height, light, noise, and other characteristics.

g. If the system is enhanced with computer recording capabilities, use software that can be easily modified and that will meet all users' needs.

h. Fully understand the operation and maintenance of the equipment and take full advantage of manufacturers' training courses when offered.

i. Start early in the purchasing process to fulfill NRC requirements for a General or Specific License.

$j$. Verify that meter service is available and that the manuals on the dredge are the same as the ones used by the service technician; determine the hours when this service is available.

Preplanning and good communication with the instrument vendor are essential to minimize problems that may arise during the installation of new dredge production meters and instrumentation (Pankow 1991). 


\section{Evaluation on Hopper Dredge Wheeler}

Field tests were conducted by the DRP on the hopper dredge Wheeler to evaluate the accuracy and reliability of production meters used when dredging in a fine-grained sediment environment (Scott 1992). Hopper loads were calculated from production-meter data for comparison to load calculations performed by the more conventional method of using a load-displacement system also installed on the dredge. This study provided data for users of production meters on hopper dredges to more accurately calculate real-time dredge production during dredging operations.

It is generally accepted that in coarse materials (sand), the nuclear density meter produces accurate data. It was desired to evaluate the accuracy of such meters when dredging fine-grained materials such as silt and clay. Production meters were installed on all three drag arms of the Wheeler to record slurry velocity and density. The Wheeler was dredging a fine- to medium-grained silt sediment at Sabine Pass near Port Arthur, TX. The sediments around Sabine Pass have an average in-place density of about $1.47 \mathrm{~g} / \mathrm{cm}^{3}$.

\section{The Wheeler}

The Wheeler is a large trailing suction hopper dredge with a length of more than $400 \mathrm{ft}$. Three drag arms, two side drag arms with 28 -in. suction pipes and a center drag arm with a 42 -in. suction pipe, are used to fill the 8,000-cu-yd hopper. The drag arms were each equipped with production meters consisting of nuclear density meters and magnetic velocity meters.

The production meters were installed on the Wheeler by IHC Holland. The production-meter system was manufactured by Observator, a Dutch company. Magnetic velocity meters are intrusive meters with electrodes penetrating the pipe wall. The meters require installation of a separate pipe section into the dredge pipe. Production-meter output is directed to a processor in the pilot house and is displayed on an analog cross-point display unit. The cross-point display indicates the optimum solids flow rate in the pipe along with the production rate of material in the pipe.

\section{Production-meter data acquisition}

A PC with an RS232 data-acquisition interface was used to log the production-meter data. Software developed by WES recorded the data in binary format on the PC hard disk for storage efficiency. Software was developed with the capability of calculating real-time production (cubic yards in place) and providing output of production as a function of time. The program can be changed to calculate the total production and display it for any time interval during the dredging cycle. Both the density meters and velocity meters were sampled every second, with 10 -sec data averages recorded in the data files. Recording 10-sec averages in binary format allowed the data to be 
recorded for months at a time before the hard disk reached its full capacity. Commercially available software was used to reduce and analyze the field data.

\section{Load-measurement system}

A load-displacement monitoring system was installed on the Wheeler to measure the load in the hopper. This system uses a hydrostatic pressure bubbler gas system attached at the bow and stem of the vessel to relate the hydrostatic pressure change to vessel draft and then convert draft to hopper load through vessel load-displacement tables. The bubbler pressure output is converted to load and displayed on a chart recorder in the pilot house. Load data, along with measurement of the volume of water in the hopper before the loading begins, are used to calculate the production of each load in in-place cubic yards. The system is calibrated by filling the hopper with water of a known density and recording the total weight of water for a full hopper with a volume of $8,000 \mathrm{cu}$ yd. Water calibration tests performed by WES indicate that the load-displacement system was capable of measuring the load with an accuracy of approximately 2 to 5 percent.

\section{Test and analysis}

Twenty-three loads recorded within a 2-day period were analyzed for this study. The analysis consisted of comparing hopper-load data from loaddisplacement measurements with production-meter load calculations resulting from the production-meter data-acquisition process. The analysis was performed in two parts: (a) a comparison between the calculation of average density of material input into the hopper per load using the two methods, and (b) a comparison between the calculation of total load in the hopper.

To calculate the average pumped slurry density with the load-chart data, the weight of material pumped into the hopper (from the load chart) was divided by the hopper volume available for the slurry. The hopper volume available for the slurry was the total hopper volume $(8,000 \mathrm{cu}$ yd) minus the bin water volume in the hopper before filling. The total load pumped into the hopper was the load recorded from the load chart.

Slurry density and slurry velocity in the pipeline over the load cycle were determined by the computer. Because of the fine silt sediments being dredged, no overflow was allowed. To accurately calculate the average inflow density and cumulative load pumped into the hopper, starting and stopping times were required for the calculations. The Wheeler is equipped with an automatic light mixture overboard system that automatically opens a valve to direct the flow overboard when the density of the mixture falls below $1.05 \mathrm{~g} / \mathrm{cm}^{3}$. When the density of slurry in the pipeline exceeds $1.05 \mathrm{~g} / \mathrm{cm}^{3}$, the filling cycle begins.

During the production-meter tests, ultrasonic surface detectors were installed over the Wheeler hopper to measure the level of material in the 
hopper. Data from these sensors indicated when the level of material in the hopper reached the top of the overflow weirs. This point in the filling cycle was used as the end point for the production-meter load calculations.

To calculate the average density of slurry pumped into the hopper, density records for each load were analyzed. All density data recorded for a particular load were summed and then divided by the number of points recorded. To calculate the total load pumped into the hopper, each data point recorded for velocity and density was incrementally summed within an equation describing mass flow to calculate the slurry load in long tons.

\section{Study results}

Results of this study are presented in Table 5. The 23 loads are listed with load-meter and production-meter comparisons of average hopper load density in grams per cubic centimeter, and total hopper load in long tons. Average hopper load densities calculated by the load-displacement meter and the production meter have almost identical mean values, 1.298 and $1.295 \mathrm{~g} / \mathrm{cm}^{3}$, respectively, and have an average standard deviation of 0.0367 and $0.0369 \mathrm{~g} / \mathrm{cm}^{3}$, respectively, indicating a strong correlation between the two data sets. On the other hand, the total load data comparison between the two methods reveals that the mean production-meter total load calculation (7,454 long tons) is approximately 20 percent higher than the mean load-meter measurement $(6,213$ long tons). Also, the standard deviation is substantially higher for the production-meter data (465.1 long tons) as compared to the load-displacement meter data (182.3 long tons).

This difference in total load may be explained by the condition of the hopper doors during the study period. About 2 weeks after the study, the Wheeler experienced a failure of one of the hopper doors to close, requiring emergency repairs. It is conceivable that the door was experiencing problems with closure during the study period, requiring a longer fill time and subsequently a higher load indication by the production meter (material was simply being recycled through the hopper dredge back to the channel bottom). The production-meter data indicate an almost threefold higher standard deviation from the mean than the load meter data, thus reflecting the varying capability of the hopper to hold its load if the hopper doors were not closing properly during the study period.

Total load calculations with the production meter require an integration of velocity and density measurements over the dredging cycle. This requires an accurate method of slurry velocity measurement, such as the magnetic velocity meter. These meters, when properly calibrated and serviced, have proven to measure velocities to accuracies of less than 1 percent of full scale. The use of production meters for calculating production on a load-to-load basis for hopper dredges may be limited due to overflow and leakage through hopper doors, but for calculating the total production of dredged material through the 


\begin{tabular}{|c|c|c|c|c|}
\hline Load & $\begin{array}{l}\text { Average Load- } \\
\text { Meter Density } \\
\text { gm/cu cm }\end{array}$ & $\begin{array}{l}\text { Average } \\
\text { Production-Meter } \\
\text { Density } \\
\mathrm{gm} / \mathrm{cu} \mathrm{cm}\end{array}$ & $\begin{array}{l}\text { Load-Meter Load } \\
\text { long tons }\end{array}$ & $\begin{array}{l}\text { Production-Meter } \\
\text { Load } \\
\text { long tons }\end{array}$ \\
\hline 1 & 1.272 & 1.237 & 6,100 & 7,698 \\
\hline 2 & 1.272 & 1.281 & 6,100 & 7,558 \\
\hline 3 & 1.272 & 1.283 & 6,100 & 7,055 \\
\hline 4 & 1.272 & 1.267 & 6,100 & 7,480 \\
\hline 5 & 1.272 & 1.310 & 6,100 & 7,679 \\
\hline 6 & 1.304 & 1.349 & 6,250 & 8,009 \\
\hline 7 & 1.356 & 1.339 & 6,500 & 7,762 \\
\hline 8 & 1.314 & 1.343 & 6,300 & 7,328 \\
\hline 9 & 1.356 & 1.317 & 6,500 & 6,917 \\
\hline 10 & 1.314 & 1.346 & 6,300 & 7,477 \\
\hline 11 & 1.314 & 1.313 & 6,300 & 8,299 \\
\hline 12 & 1.252 & 1.238 & 6,000 & 7,466 \\
\hline 13 & 1.252 & 1.262 & 6,000 & 7,787 \\
\hline 14 & 1.314 & 1.285 & 6,300 & 7,095 \\
\hline 15 & 1.293 & 1.296 & 6,200 & 7,269 \\
\hline 16 & 1.272 & 1.264 & 6,100 & 6,424 \\
\hline 17 & 1.397 & 1.314 & 6,700 & 7,649 \\
\hline 18 & 1.335 & 1.336 & 6,400 & 6,731 \\
\hline 19 & 1.293 & 1.303 & 6,200 & 7,824 \\
\hline 20 & 1.283 & 1.214 & 6,150 & 6,615 \\
\hline 21 & 1.252 & 1.295 & 6,000 & 7,718 \\
\hline 22 & 1.293 & 1.277 & 6,200 & 7,771 \\
\hline 23 & 1.293 & 1.315 & 6,000 & 7,842 \\
\hline Mean value & 1.298 & 1.295 & 6,213 & 7,454 \\
\hline $\begin{array}{l}\text { Standard } \\
\text { deviation }\end{array}$ & 0.0367 & 0.0369 & 152.3 & 465.1 \\
\hline
\end{tabular}

pipeline for a given project, production meters can provide a reliable and accurate measurement of dredge production (Scott 1992). 


\section{Silent Inspector ${ }^{1}$}

The Corps of Engineers depends almost completely on inspectors for quality control and performance monitoring of contract dredging. Automated inspection tools ("silent inspectors") are one way to assist inspectors, reduce the cost of responding to claims, and make dredge-production records more standard, accessible, understandable, and usable. An effective automated dredge monitoring system can provide useful unbiased information to all parties involved in dredging activities (Rosati and Welp 1994).

A dredge-operations silent inspector (SI) system to automatically log data from instruments generally maintained aboard hopper dredges, compute the dredging activities occurring and the quantity of material retained, and provide summaries of this information in both reports and graphical displays, has been developed by the DRP (Cox, Maresca, and Jarvela (in preparation)) and is currently undergoing testing and improvements. While the system is currently designed for use aboard hopper dredges, its basic concept could be applied to other dredge types in the future. The main output of the SI is a series of dredge-operation data summary reports.

\section{SI System Concept}

Increased environmental awareness has led to stricter standards for regulation and monitoring of dredging operations, primarily in documenting the location of the dredge during both dredging operations and open-water disposal of the dredged material. The position of the dredge during dredging and disposal operations must often be proven from recorded information. In the past few years, budget cutbacks have reduced the number of personnel available for inspection of dredging activities while at the same time, the number of dredging contracts has increased. Irregular and seasonal dredging workloads have also made it difficult to provide an adequate number of trained inspectors on a timely basis. This has resulted in some cases where the Corps has had to rely solely on contractor-supplied information rather than on independently recorded information to determine the validity of contractor claims.

1 Chapter 5 was extracted from Cox, Maresca, and Jarvela (in preparation) and Rosati and Welp (1994). 
The concept of providing dredge inspectors with an electronic tool for the automated collection, analysis, display, and reporting of information about a dredge's activities would allow inspectors and contract administrators to better - assess contractor performance, especially when the inspector is not aboard the dredge. Recent progress in electronic instrumentation and data-logging systems makes it possible to collect and preserve information with greater detail and accuracy than ever before.

\section{System requirements}

A survey was conducted of dredging managers at Corps Headquarters, Division, and District offices to determine desired SI output requirements. Based on the survey, it was recommended that an SI system should:

a. Use existing sensors and interface standards as much as possible.

b. Focus initially on hopper dredges, with future expansion of the system to include other types of dredges.

c. Require neither additional personnel nor extensive training of existing personnel to use.

d. Facilitate importation of data from sources other than the dredge dataacquisition system.

e. Be expandable to meet future needs.

f. Produce data products that are useful for managing existing and future Corps dredging projects.

g. Have a standard set of capabilities for general use but also have a provision to add any unique capabilities needed by individual Districts.

$h$. Provide a reasonable level of assurance that the correct data were obtained from the contractor and that the SI data were not altered after they were initially recorded.

i. Avoid use of proprietary technology.

The survey revealed that most hopper dredges already have most of the sensors needed to implement the SI. Production and management of standard reports are the primary ways the SI fulfills the system requirements.

\section{System performance}

The SI uses state-of-the-art computer hardware and software to simultaneously measure several parameters of the dredge's activities, display this 
information, automatically produce Corps dredging reports, and provide a permanent and transferable copy of this information. The system produces a factual record of the dredge's activities that is sufficient for dredging inspectors to accurately assess contract performance even in the absence of a fulltime onboard inspector. To do this, the SI performs the following:

a. Measures a suite of information about dredging activities that will enable the system and dredge inspectors to accurately assess the activities the dredge performed versus time and location and to assess adherence to contract requirements.

b. Automatically creates dredging reports, such as trip (load), daily, and job reports, from the collected data.

c. Measures, records, and reports dredging information in a standardized format for similar types of dredges to allow the data to be transferred easily between all Corps District offices.

d. Provides a means to electronically archive the data collected and transfer them to users working on other hardware and software mediums.

$e$. Provides graphical display of collected data by time or location.

f. Provides a Corps-generated independent database of dredging activities for use in settling claims brought by contractors against the Corps.

g. Provides flexibility and extendibility to meet changing system requirements and to meet each District's unique system requirements.

h. Allows Corps users to add individual features without destroying the integrity or operation of the basic system.

$i$. Provides the Corps a more accurate assessment of dredging activities, downtime, and production rates for more accurate estimating of future project costs and budgets.

\section{SI System Overview}

The current version of the SI system was designed to work on hopper dredges to perform the following functions:

a. Record data on several aspects of dredging operations.

b. Properly label the data with the project name, contract ID, dredge name, trip (load) number, and dredging and disposal locations. 
c. Compute the type of dredging activity occurring aboard the dredge at any time, as well as the amount of material recovered in terms of tons dry measure (TDM).

d. Automatically provide summaries of the trip (load), daily, and job-todate dredging activities on a similar basis to reports in use today.

e. Graphically display recorded data.

f. Archive the data for transfer to other SI systems and for permanent record keeping.

\section{Hardware and software requirements}

The SI system for hopper dredges operates on the Unix operating system and 486 PCs. The system software was designed to require minimal or no user knowledge of the Unix operating system or commercial software packages utilized within the system. User interactions with the system are via a graphical user interface that allows easy setup, operation, and data review.

Hardware. The SI hopper dredge system is designed to be used on PCs because they are commonly used throughout Corps Districts. Communication between computers is based on Ethernet. The system is composed of three components: dredge-specific software (DSS); SHIP; and SHORE. The following computer hardware is necessary for the designated components to ensure proper operation: (a) $486 \mathrm{PC}$ with minimum 33-MHz clock, VGA graphics, standard monitor, 500-MB hard drive, 32-MB RAM (DSS, SHIP, SHORE);

(b) Ethemet link (DSS, SHIP); (c) Postscript laser printer (SHIP, SHORE);

(d) streaming tape drive and tapes (SHIP, SHORE); and (e) uninterruptable power supply (DSS, SHIP).

Software. The SI system was developed using several commercial software packages. These packages provide the graphical user screens and database engine on which the system is built. Consequently, each component of the system needs to access these commercial packages to operate properly. The following software packages must be purchased and installed on the DSS, SHIP, and SHORE components for the system to work: (a) SCO Unix with Open Desktop; (b) SL-GMS; and (c) Sybase relational DBMS (2-8 users).

\section{Operational components}

DSS component. The SI system is designed to accept specific types of data about hopper-dredge operations into its central database. Each hopper dredge contains a different suite of instrument types and locations, calibrations, data formats, and types of data available; thus, actual sensor data must be converted into engineering units, assessed for validity, and, in some cases, 
additional information must be computed to provide the required data inputs into the central database.

While the output of each DSS is identical, input to a DSS generally will vary from dredge to dredge; therefore, no two DSS units are expected to operate internally in exactly the same way. The DSS resides onboard the dredge. Cox, Maresca, and Jarvela (in preparation) describe the DSS developed for the training and reference SI system for hopper dredges. That particular DSS software resides on the same computer as the SHIP component, but it can operate on a separate computer.

SHIP component. The SHIP component is the heart of the SI system. Like the DSS, it resides onboard the dredge. Required measured data are received from the DSS and are inserted into the system's central database. The SHIP system also performs the following:

a. Displays the incoming data in real time.

b. Computes and records the current dredging operation, called the dredge state, as well as the amount of material retained (TDM).

c. Automatically creates standard trip, daily, and job reports based on the recorded data.

d. Graphically displays any measurement data contained within the database.

e. Automatically backs up and archives data.

f. Permits the user to input information concerning the dredging project, dredge, its crew, dredging and disposal areas, and local marine landmarks.

Data recorded by SHIP are then transferred to a SHORE component to allow more detailed data analysis and intercomparison with data from other SHIP units.

SHORE component. The SHORE component is quite similar to SHIP, with the following exceptions:

a. SHORE does not contain real-time data-collection capability.

b. SHORE is able to input and review multiple dredging project data sets.

SHORE executes on shore-based computers and provides data manipulation and analysis, generates reports, and creates graphics using the same software suite as SHIP. The user interface is nearly identical to the ship-based user interface. The major difference is the absence of the data-monitoring user interface screens. Multiple SHIP data sets can be input into SHORE. Each 
remains unique based on the project name, contract ID, and dredge name assigned to the data.

\section{SI System Capabilities}

\section{User entry of project and dredge Information}

Information related to a dredging project, including the dredge name and characteristics, crew, designated dredging and disposal areas, and landmarks related to the local marine waters are entered into the system by the user. Information the user can enter includes:

a. Project data:

(1) Project name.

(2) Contract number (ID).

(3) Contractor name.

(4) Corps of Engineers District name.

(5) Project type: new work or maintenance.

(6) Anticipated start/finish dates.

b. District data:

(1) Corps of Engineers District name.

(2) Abbreviations for the District name.

c. Dredge data:

(1) Dredge name.

(2) Dredge owner name.

(3) Dredge type.

(4) Year built.

(5) Vessel beam.

(6) Vessel length. 
(7) Vessel dredge pumps horsepower.

(8) Vessel displacement: empty and full.

(9) Vessel maximum speed: empty and full.

(10) Vessel draft: fore and aft when empty and loaded.

(11) Distance to draft sensors along vessel hull.

(12) Hopper maximum capacity.

(13) Distances in hopper to ullage sensors.

d. Crew members.
(1) Name.
(2) Rank.
(3) Initials (ID).

e. Dredging areas (stations).

(1) Dredging area name.

(2) $\mathrm{x}, \mathrm{y}$ coordinates forming rectangle to represent dredging area.

f. Disposal areas.

(1) Disposal area name.

(2) $x, y$ coordinates forming rectangle to represent disposal area.

g. Landmarks.

(1) Landmark name.

(2) $x, y$ coordinates of landmark location.

\section{Measurements collected by the SI system}

DSS is required to insert into the SHIP database a required set of data concerning the hopper dredge's operations. To do this, the DSS obtains data originating from many instrument systems aboard the dredge, attaches a data quality indicator to the data, and computes data values needed by SHIP that are not directly measured. The following data are the required inputs from DSS into the SHIP database (measured parameters and units): 
Project name

Contract ID

Dredge name

Date

$\mathrm{mm} / \mathrm{dd} / \mathrm{yy}$

Time

Vessel speed

hr:min:sec

Vessel heading

Vessel position ( $x$ coordinate)

knots

Vessel position (y coordinate)

degrees

feet

feet

Hopper door status

Pump-out status

Vessel draft-aft

Vessel draft-forward

Water depth

Port suction pump

Port-side material recovery

Port-side draghead depth

Starboard suction pump

Starboard-side material recovery

open or closed

on or off

feet

feet

feet below ship

on or off

true or false

feet below ship

on or off

true or false

Starboard-side draghead depth

feet below ship

\section{Data calculations made within SHIP}

The SHIP unit computes two items: (a) the dredging operation underway, called "dredge state," and (b) the TDM of material collected. It also sums the total time a dredge is operating in each dredge state for reporting within the system's standard reports.

Dredging state. The SHIP component software is designed to try to calculate the status of dredging operations for each new set of measured data it receives from the DSS every $10 \mathrm{sec}$. The system tries to automatically calculate the dredge states (which are currently tracked by hand for Corps projects) and total time spent performing each activity. It can then produce summaries (reports) of individual trips, days, and jobs that are identical to the current reporting requirement. Seven dredge states the system identifies are:

a. Dredging.

b. Tuming.

c. Sailing to dump (disposal) area.

d. Dumping.

e. Sailing to dredging area. 


\section{f. Downtime.}

\section{g. Pumping out material.}

The information provided by the DSS to the SHIP unit and the computational equations within SHIP can determine most of the dredge states accurately and consistently. The two exceptions are turning and downtime. Turning (presently defined by the Corps as turns between dredging cuts) is difficult to distinguish from sailing to dump and sailing to dredging area. Downtime (as presently reported by the Corps) cannot be distinguished from other nondredging states based on sensor data alone. The system will also decide that the dredge is in a downtime state whenever key measured data are missing from a data set.

\section{TDM of material recovered}

SHIP calculates the TDM of material in the hopper based on measured data collected at the end of the last dumping event and on data displayed on the Dredging Operations screen. A plot of TDM versus time from the end of the last dumping event is provided. The screen will scroll whenever the TDM plot reaches the right side of the plot, so that the newly arriving information continues to be visible on the left side of the plot.

TDM is calculated automatically by the SHIP component based on an assumed specific gravity of individual sediment particles, the displacement of the vessel from one load to another, and volume curves for the vessel's hopper. This calculation cannot be changed except by a systems engineer.

\section{Data reporting}

The SI system provides computer-generated reports that generally display the same information as is currently compiled manually for Corp projects and contracts.

Trip report. The trip report breaks down into the time required for dredging, hauling to disposal area, disposing material, retuming to the dredging area, tuming, shore delivery, and downtime. It contains the project's contract number and name, dredge name, trip (load) number, start times and locations when the dredge changed activities (dredge states), along with specific information on the dredge's status such as the vessel's heading, speed, draft, and pump status. The time spent in each dredge state, the total trip time, and the TDM of material retained are computed and presented at the end of each trip report.

The trip report begins when the dredge starts its transit to a dredging area and ends when dumping of the dredged material is completed. When a trip covers portions of two days, the trip information is covered in one report, not split into two trips. 
Daily report. The daily report summarizes time spent in each dredge state for each trip conducted during a day. The total TDM of material per trip, per minute of pumping, and per elapsed minute are also presented. Each quantity presented is summed for the day, and an average per load is displayed. A breakdown of downtime events is presented for those downtime categories currently reported manually.

The daily report includes information from all trips that begin during the day of the report. For trips that last until the following day, the entire quantities of dredging activity times and material dredged are contained in the daily report corresponding to the start of the trip.

Job report. The job report summarizes information contained in the daily reports over the life of the job through the end date specified by the user. The job report also presents project cost information so as to more clearly resemble the Form 27 in use today. However, this cost information is not automatically generated by the system. It must be entered by the user.

Information to generate the job report is maintained in the system at all times. However, printing of a job report must be initiated by the user. The report includes all trips, beginning with trip number 1 through the last completed trip for the end date of the report. Most of the data contained within the system's database can be plotted versus time for easy review. Data-overlay capability exists for values with the same units of measure.

\section{System security}

The SI system has several security features built in to ensure the integrity of collected data and to restrict use to authorized personnel. The primary security feature is password-controlled access to different levels of the system. For example, dredge personnel have access only into the data monitoring screen and review of downtime events, plus the ability to designate downtime events by cause and add to related comments. Dredge inspectors will normally have full access to all user screens, data report and display functions, and data transfer and archiving operations. Dredge inspectors are not able to modify the measured data in any way. Access to the system's software code and database language is limited to designated SI system software maintenance personnel at WES. Access to the various levels, with the exception of the system software and database code, is controlled by Corps District personnel using the password feature.

System security also consists of ensuring that the data entered into the system are both accurate and consistent. The DSS portion of the system performs, at a minimum, range checks of incoming data to minimum and maximum acceptable values. A data status for each piece of data sent to the SHIP database is computed and tagged to that data. The SHIP portion of the system performs additional data-consistency checks. However, only by inspector verification to test data accuracy, and the mandating of various dredge actions 
to test data consistency (hopper water fill tests, for example) before and during a dredging project, can data integrity be ensured.

\section{Data backup, archiving, and transfer}

To ensure that data are not lost during data collection due to a system failure or full disk, an automatic data backup and recovery feature is included in the system. This feature provides for periodic dumps of the entire contents of the central database. These dumps are nondestructive and can occur while

normal database processing is in progress. In between these complete database dumps, log files of all database transactions that modify the database are maintained automatically.

Transferring data from the data-collection site onboard a dredge to the District office, or between offices, is performed using the data-archive function. Archiving data converts the data into a transferable Unix file format and deletes the archived data from the database. The user must then copy these files to tape or other archival media for transfer to shore, where the data can be reloaded into an SI shore-based system for data display and analysis. The backup and archival data files both have unique formats so that the data must be reloaded into and accessed via an SI system.

\section{Data accessibility using DOS/Windows programs}

Because of the numerous new software products (especially DOS/Windows products) coming to market that provide easy development of custom graphical displays and reporting capabilities, these types of features have not been developed within the SI system. Instead, the approach has been to develop the system around a database that can interact with other programs given a common interface format.

The SI system is built around Sybase relational database software. Many new DOS/Windows software packages are providing the proper interface tools to connect to the system's central database. In particular, DOS/windows programs would need to contain the Open Database Connectivity driver that the Sybase database supports.

User interactions with the SI system and database will continue to be safeguarded through the system's security feature. No access by an external program will be permitted without a proper User ID and password. Complete instructions for starting and operating the three components (DSS, SHIP, SHORE) of the SI system are provided by Cox, Maresca, and Jarvela (in preparation). 


\section{Fleld developmental tests on the Essayons}

The SI system was successfully tested aboard the Corps hopper dredge Essayons. The system generated trip and daily reports automatically. It gathered data from a data-acquisition system already existing aboard the dredge. TDM was computed successfully in real-time on the dredge.

The SI had a problem resolving the turning state. Much of the time spent in a turn is not spent actually changing heading, but in raising and lowering the drag arms. It is difficult to distinguish between the sailing-full state when the dredge is in a turn or traveling to a dump site. The problem was solved by a change in dredge state logic that put the dredge in an intermediate maneuvering state before the sailing-full and turning states are determined (by either a dump occurring or a turn) (Rosati and Welp 1994). 


\section{Synopsis}

The research described in this summary report pertains to the need for measuring and reporting offshore onsite water levels and for an enhanced vessel heave system for dredging purposes. The development of a real-time, 3-D navigation system with 1-dm (4-in.) accuracy for hydrographic surveying based on NAVSTAR GPS is described. Laboratory and field tests of production meters were conducted to ascertain the accuracy and reliability of production meters for dredges under various dredging conditions, and the concept development and operational aspects of an SI for automatically monitoring contract hopper dredges are presented.

\section{Integrated Vertical Control}

Dredging operations, as well as dredge monitoring and contract payment, require the accurate measurement of bathymetry referenced to a static datum. Real-time availability of the mean water level and compensation for the waveinduced vertical motion of the vessel are required to accomplish these activities.

\section{ARTTES}

A long-standing problem associated with coastal and offshore dredging operations has been accounting for tidal effects in hydrographic surveys and in the dredging process to ensure that design channel depth has been reached without excessive overdredging and to aid determination of the quantity of material moved to compute payment. WES developed the ARTTES based on predictor-corrector methods. The system consists of a high-precision waterlevel sensor linked to a VHF transmitter that continuously broadcasts the water level at the dredging site, which may be up to 20 miles offshore. The predicted water level is corrected for nontidal (meteorological) effects, which allows dredge operators to make online adjustments for changes in water level, thus minimizing the need to overdredge.

Present procedure. As presently implemented, ARTTES uses a completely deterministic procedure for predicting the tide. When the differences 
between the predicted tide and observed level exceeds some predetermined value, user access to the system is denied. Periods of user-access denial usually occur when sea conditions are unfavorable or unsuitable for survey operations. Dredging operations, however, may continue in weather conditions unsuitable for survey operations. Because ARTTES is used by dredge operators, it is desirable to minimize periods of user-access denial. The present procedure for predicting the tide is based upon the harmonic method of tide analysis and prediction. However, a portion (residual) of the water level is not described by this method. Most of this residual is the result of short-term meteorological effects.

ARTTES enhancements. The approach used by Borgman, Garcia, and Walton (1993) for improving ARTTES predictions may be described as "hybrid" in that the astronomically forced component of the tide is analyzed and predicted in the traditional manner (harmonic analysis), while the shortterm meteorological component is analyzed and predicted via statistical techniques. By using combinations of levels of threshold exceedence and duration, practical aspects of the dredging process may be taken into account. The dredging operator may deem it preferable to permit a relatively high level of threshold exceedence for a relatively short time (say an estimated duration of $1 \mathrm{hr}$ ), rather than deny access. The duration limit is based upon knowledge of the history of site water-level data and engineering judgment.

\section{Second-generation vessel-motion system (VMS-II)}

Vertical-motion systems (heave compensators) for use in hydrographic survey applications presently exist in various forms. However, the current generation typically operates in the time domain, which results in inherent limitations, including very expensive custom-designed electromechanical components. Time-domain techniques produce an unavoidable phase lag. For real-time applications, the phase lag is unacceptable. Research by Carter et al. (1995) was directed toward a frequency-domain-based second generation (VMS-II) that uses commercially available sensors, and the phase lag was eliminated.

Developing future data. Double integration in the frequency domain can produce large errors if the data point of interest is not at the center of the data string. However, real-time applications require the data point of interest to be at the beginning of the data string. Placing the data point of interest at the center of a real-time data set requires data that have not yet been measured (future data). A practical approach to providing estimates of future data was developed by Borgman and Scheffner (1991). The process of developing future data consists of constructing an extrapolation of the real data into the future with the data point of interest being the center of the data set composed of the real and future data.

VMS-II. Digital signal-processing technology has evolved to the stage where its use will satisfy VMS-II processing requirements. VMS-II utilizes 
the signals from standard off-the-shelf sensors for vertical acceleration, pitch, and roll. The inputs from these sensors are input to a custom-designed circuit board that contains an analog low-pass filter, DSP processor, required memory, and ancillary components all configured in a PC. The software for VMS-II is written in two parts. An assembly language code is installed in the firmware of the system to perform communications and other operations, while the main processing software is written in "C."

\section{Horizontal/Vertical Positioning System Utilizing GPS Satellite Constellation}

Presently, horizontal positions of dredges and survey vessels are determined using systems that electronically measure multiple ranges or ranges and angles from previously established control points on shore. Most of these systems require the vessel to occupy a calibration point installed near the job site each work day to initialize the system. Maintaining these control stations, moving receiver/transmitters about, and performing the calibration process is extremely expensive and labor-intensive. In addition, all dredging and survey operations are vertically referenced to the vessel performing the work.

In the late 1980s, Geier, Loomis, and Kleusberg (1992) determined that a system requiring no onsite calibration and only one reference station would significantly increase the efficiency and productivity of Corps hydrographic surveying. Such a system would have to provide a horizontal positioning accuracy of $\pm 2 \mathrm{~m}$, and a vertical accuracy of $\pm 0.1 \mathrm{~m}$. In the opinion of Wells and Kleusberg (1992) in 1989, the feasibility of decimeter accuracies from GPS depended to a large extent on the feasibility of being able to realize the high precision of ranges derived from carrier beat phase measurements by resolving carrier ambiguity and either preventing or reliably correcting carrier cycle slips. With deployment of a 24-satellite NAVSTAR GPS constellation in the mid-1990s, the possibility for a kinematic GPS positioning system meeting those requirements materialized.

\section{GPS}

The ultimate limitation on GPS positioning accuracy is not the accuracy with which GPS range measurements can be made, but the effects of biases and errors on these measurements. Many of these biases have a high spatial correlation. Errors in point positioning of each of two receivers will have almost the same magnitude and orientation, but the error in position of one relative to the other will be much smaller. This is the basis of differential GPS: more than one receiver must be used, and the coordinates of at least one of the receivers must be known.

This was the technique used in developing the Corps of Engineers real-time OTF DGPS positioning system by the DRP. Carrier ambiguity-resolution 
realized the full precision of carrier measurements by resolving carrier biases and errors and preventing or reliably correcting cycle slips. Only one fixed reference station of known coordinates ( $x, y, z$ positions) is necessary for the user station to operate with the decimeter-level precision required for Corps surveying and dredging activities.

\section{Corps of Engineers real-time OTF DGPS system}

The Corps DGPS system provides real-time 3-D positions with horizontal and vertical accuracies better than $10 \mathrm{~cm}$ over ranges up to $20 \mathrm{~km}$ from a single known station without static initialization. The project has passed from concept development through feasibility studies, system analysis, resolution of carrier ambiguities OTF, to final system integration. The real-time OTF prototype delivers high-precision kinematic positioning accurate to about $2 \mathrm{~cm}$ at the antenna phase center, while simultaneously providing a separate output for meter-level DGPS for navigation purposes. As a design constraint, the OTF system was developed using only equipment that could be purchased off the shelf. The OTF software is the heart of the system and was the focus of much of the development effort. The software was designed to require minimum operator attention and has several built-in quality-control procedures to ensure that the high performance and reliability of the system are maintained.

\section{Corps real-time OTF GPS avallability}

Centimeter-level accuracy is a reality in real-time. Operational prototype field tests onboard survey vessels and the hopper dredge Essayons have demonstrated that this technology will have a great impact on surveying, navigation, and dredging activities. This particular system is robust, reliable, and easy to use and has surpassed its original design-goal specifications. Tests have shown that real-time tide corrections using OTF are possible; this is very important for the dredging industry. The system is also a valuable engineering tool for those operations for which postprocessed data will suffice. In reality, it has been demonstrated that real-time OTF is as easy to provide as DGPS within the current range limitations of $20 \mathrm{~km}$.

\section{Production-Meter Technology}

A dredge production-meter system consists of a density meter, a velocity meter, an easy to visualize and understand output display, and a means of recording, storing, and totaling the data. The velocity meter and the density meter together estimate dredge production. The accuracy of this estimate is a function of the individual meters. Production-meter information can be used to increase dredge production and improve overall dredging efficiency. 
There are several types of velocity and density meters, each with its own level of accuracy. Calibration is performed at the factory by company representatives using an average type slurry. As the slurry type changes under real dredging conditions, output information from the sensors will vary.

\section{Laboratory tests}

Production (velocity and density) meters identified in a worldwide survey as being used onboard operating dredges were laboratory tested at GIW to evaluate instrument performance under controlled conditions of slurry type, concentration, flow, and pipe orientation (Pankow 1989). All test meters were installed and calibrated according to manufacturers' procedures by the manufacturers' factory technicians.

The nuclear density meter is the only readily available densitometer used on contemporary dredges. It is reliable, accurate, and safe to use. However, it does employ a radioactive source and therefore a Nuclear Regulatory Commission license is required. For dredge production, the most reliable instruments for measuring slurry flow and density are the magnetic velocity meter and the nuclear density meter.

\section{Fleld tests}

Production meters were installed and operated on the dustpan dredge Jadwin and hopper dredge Wheeler to determine reliability of operation under two different material conditions. The Jadwin was operating on the Mississippi River in sand material, while the Wheeler was dredging Sabine Pass, TX, removing silt and clay sediment.

Jadwin production tests. Tests aboard the Jadwin were used to better understand the effects of dredge-pump speed and dustpan water-jet pressure on dredging ability. The experience produced several recommendations for the planning, purchasing, installing, and functioning phases of production-meter operation. Preplanning and good communication with the instrument vendor were found to be essential to minimize problems that may arise during the installation of new dredge production meters and instrumentation (Pankow 1991).

Wheeler production tests. Wheeler hopper loads were calculated from the production-meter data for comparison to load calculations performed by the more conventional method of using a load-displacement system also installed on the dredge. It is generally accepted that in coarse materials (sand), the nuclear density meter produces accurate data. It was desired to evaluate the accuracy of such meters when dredging fine-grained material such as silt and clay. 
Average hopper load densities calculated by the load-displacement meter and the production meter had almost identical mean values and standard deviations, indicating a strong correlation between the two data sets. For these tests, the total load comparison was at least 20 percent different. It was later determined the hopper doors were not closing properly, and the production meter was calculating material that was actually being discharged back into the water column prior to filling the dredge hoppers.

Comparison. The use of production meters for calculating production on a load-to-load basis for hopper dredges may be limited due to overflow and leakage through hopper doors, but for calculating the total production of dredged material through the pipeline for a given project, production meters can provide a reliable and accurate measurement of dredge production. The velocity meters, when properly calibrated and serviced, proved to measure velocities to accuracies of less than 1 percent of full scale.

\section{Silent Inspector}

The Corps depends almost entirely on inspectors for quality control and performance monitoring of contract dredges. Automated inspection tools ("silent inspectors") are one way to assist inspectors, reduce the cost of responding to claims, and make dredge-production records more standard, accessible, understandable, and usable. An SI system to automatically log data from instruments generally maintained aboard hopper dredges, compute the dredging activities occurring and the quantity of material retained, and provide summaries of this information in both report and graphical displays has been developed (Cox, Maresca, and Jarvela (in preparation)).

\section{System requirements}

A survey was conducted of dredging managers at Corps Headquarters, Division, and District offices to determine desired SI output requirements. Based on the survey, it was recommended that an SI system should: (a) use existing sensors and interface standards as much as possible; (b) require neither additional personnel nor extensive training of existing personnel to use; (c) facilitate importation of data from sources other than the dredge data-acquisition system; and (d) provide a reasonable level of assurance that the correct data are entered and cannot be altered. The production and management of standard reports is the primary way the SI fulfills the system requirements.

\section{System performance}

The SI system produces a factual record of a dredge's activities that is sufficient for dredging inspectors to accurately assess contract performance even in the absence of a full-time onboard inspector. To do this, the SI 
performs the following: (a) measures a suite of information about dredging activities that will enable the system and dredge inspectors to accurately assess the activities the dredge performed versus time and location and to assess adherence to contract requirements; (b) automatically creates dredging reports, such as trip (load), daily, and job reports, from the collected data; (c) measures, records, and reports dredging information in a standardized format for similar types of dredges to allow the data to be transferred easily between all Corps District offices; (d) provides graphical display of collected data by time and location; and (e) provides a Corps-generated database of dredging activities for use in settling claims brought by contractors against the Corps.

\section{Developmental tests}

The SI system was successfully tested aboard the hopper dredge Essayons. The system generated trip and daily reports automatically. It gathered data from a data-acquisition system already existing aboard the dredge. TDM was computed successfully in real-time on the dredge. The system had a problem resolving the turning state, but the problem was solved by a change in dredgestate logic that put the dredge in an intermediate maneuvering state before the sailing and turning states are determined (by either a dump occurring or a turn) (Rosati and Welp 1994). 


\section{References}

Borgman, L. E., and Scheffner, N. W. (1991). "Simulation of time sequences of wave height, period, and direction," Technical Report DRP-91-2, U.S. Army Engineer Waterways Experiment Station, Vicksburg, MS.

Borgman, L. E., Garcia, A. W., and Walton, T. L. (1993). "Improvements to the automated real-time tidal elevation system," Technical Report DRP93-2, U.S. Army Engineer Waterways Experiment Station, Vicksburg, MS.

Carter, N. G., Grant, W. E., Hamilton, R. C., and Garcia, A. W. "Second generation vessel motion system (VMS-II)," in preparation, U.S. Army Engineer Waterways Experiment Station, Vicksburg, MS.

Cox, J. M., Maresca, P., and Jarvela, A. "Silent inspector user's manual," in preparation, U.S. Army Engineer Waterways Experiment Station, Vicksburg, MS.

Enge, P. K., and Pflieger, K. (1992). "Investigation of real-time differential global positioning system (DGPS) data link alternatives," Contract Report DRP-92-7, U.S. Army Engineer Waterways Experiment Station, Vicksburg, MS.

Frodge, S. L., Remondi, B. W., and Lapucha, D. (1994). "Real-time testing and demonstration of the U.S. Army Corps of Engineers' real-time on-thefly positioning system," Dredging Research Technical Notes DRP-4-10, U.S. Army Engineer Waterways Experiment Station, Vicksburg, MS.

Garcia, A. W. (1990). "Application criteria for the automated real-time tidal elevation system (ARTTES)," Dredging Research Technical Notes DRP4-02, U.S. Army Engineer Waterways Experiment Station, Vicksburg, MS.

Geier, G. J., Loomis, P. V. W., and Kleusberg, A. (1992). "System analysis for a kinematic positioning system based on the global positioning system," Contract Report DRP-92-8, U.S. Army Engineer Waterways Experiment Station, Vicksburg, MS.

Hales, L. Z. (1995). "Accomplishments of the Corps of Engineers Dredging Research Program," Journal of Coastal Research 11(1), 68-88. 
Lillycrop, W. J., Garcia, A. W., Howell, G. L., and Grogg, W. E. (1991). "An automated real-time tidal-elevation system for offshore dredging operations." Tidal hydrodynamics. John Wiley \& Sons, Inc., New York, Chapter $42,829-837$.

Lillycrop, W. J., Howell, G. L., Garcia, A. W., Grogg, W. E., and Andrew, M. E. (1988). "An automated real time tidal elevation system." Proceedings, U.S. Army Corps of Engineers Surveying Conference. Savannah, GA.

McNair, E. C., Jr. (1988). "The Dredging Research Program," Dredging Research Information Exchange Bulletin DRP-88-1, U.S. Army Engineer Waterways Experiment Station, Vicksburg, MS.

(1989). "Dredging Research Program of the U.S. Army Corps of Engineers." Proceedings, XII World Dredging Congress. Orlando, FL, 4450.

Pankow, V. R. (1989). "Laboratory tests of production meter instruments," Dredging Research Technical Notes DRP-4-01, U.S. Army Engineer Waterways Experiment Station, Vicksburg, MS.

(1990). "Dredge production meter survey," Dredging Research Technical Notes DRP-4-03, U.S. Army Engineer Waterways Experiment Station, Vicksburg, MS.

. (1991). "Production meter system evaluation on the dustpan dredge Jadwin," Dredging Research Technical Notes DRP-4-05, U.S. Army Engineer Waterways Experiment Station, Vicksburg, MS.

Rosati, J., III, and Welp, T. L. (1994). "Silent inspector-an aid to dredge inspection." Proceedings, Dredging '94. Lake Buena Vista, FL, 1, 756763.

Scott, S. H. (1992). "Evaluation of production meter performance in a finegrained sediment environment," Dredging Research Technical Notes DRP4-06, U.S. Army Engineer Waterways Experiment Station, Vicksburg, MS.

Wells, D. E., and Kleusberg, A. (1992). "Feasibility of a kinematic differential global positional system," Technical Report DRP-92-1, U.S. Army Engineer Waterways Experiment Station, Vicksburg, MS.

Wells, W., Wells, D. E., and Kleusberg, A. (1992). "Global position system bibliography,” Technical Report DRP-92-2, U.S. Army Engineer Waterways Experiment Station, Vicksburg, MS. 
Public reporting burden for this collection of information is estimated to average t hour per response, including the time for reviewing instructions, searching existing data sources. gathering and maintaining the data needed, and completing and reviewing the collection of information. Send comments regarding this burden estimate of any other aspect of this

\begin{tabular}{|l|l|l}
\hline 1. AGENCY USE ONLY (Leave blank) & $\begin{array}{l}\text { 2. REPORT DATE } \\
\text { September } 1995\end{array}$ & $\begin{array}{l}\text { 3. REPORT TYPE AND DATES COVERED } \\
\text { Final report }\end{array}$
\end{tabular}

\section{TITLE AND SUBTITLE}

Vessel Positioning, Survey Controls, and Dredge Monitoring Systems;

Summary Report for Technical Area 4
5. FUNDING NUMBERS

Work Unit 32492

6. AUTHOR(S)

Lyndell Z. Hales (compiler)

\section{PERFORMING ORGANIZATION NAME(S) AND ADDRESS(ES)}

U.S. Army Engineer Waterways Experiment Station

3909 Halls Ferry Road

Vicksburg, MS 39180-6199

8. PERFORMING ORGANIZATION REPORT NUMBER

Technical Report

DRP-95-9

\section{SPONSORING / MONITORING AGENCY NAME(S) AND ADDRESS(ES)}

U.S. Army Corps of Engineers, Washington, DC 20314-1000

10. SPONSORING/MONITORING AGENCY REPORT NUMBER

\section{SUPPLEMENTARY NOTES}

Available from National Technical Information Service, 5285 Port Royal Road, Springfield, VA 22161.

12a. DISTRIBUTION/AVAILABILITY STATEMENT

12b. DISTRIBUTION CODE

Approved for public release; distribution is unlimited.

\section{ABSTRACT (Maximum 200 words)}

This report summarizes research conducted under the Dredging Research Program (DRP) Technical Area 4, "Vessel Positioning, Survey Controls, and Dredge Monitoring Systems." This research addressed the need for measuring and reporting offshore onsite water levels and for an advanced vessel-heave system for dredging purposes. The automated real-time tidal elevation system (ARTTES) was enhanced to prevent access denial when threshold conditions for surveying are exceeded but may not be severe enough to preclude dredging operations. The development of a real-time, on-the-fly, 3-D navigation system with accuracy within $1 \mathrm{dm}(4 \mathrm{in}$.) for surveying and dredging based on a NAVSTAR global positioning system (GPS) is presented. Laboratory and field tests of production meters for dredges were conducted to determine reliability under different dredging conditions. A "silent inspector" system was developed to automatically log data from instruments generally maintained aboard contractor-operated hopper dredges. These data were used to compute the quantity of material retained and to provide summaries of this information in both tabular and graphic displays.

\begin{tabular}{|c|c|c|c|}
\hline \multirow{2}{*}{$\begin{array}{l}\text { 14. SUBJECT TERMS } \\
\text { ARTTES } \\
\text { Dredging } \\
\text { Dredging production meter }\end{array}$} & \multirow{2}{*}{\multicolumn{2}{|c|}{$\begin{array}{l}\text { Dredging Research Program } \\
\text { Silent Inspector }\end{array}$}} & $\begin{array}{l}\text { 15. NUMBER OF PAGES } \\
73\end{array}$ \\
\hline & & & 16. PRICE CODE \\
\hline $\begin{array}{l}\text { 17. SECURITY CLASSIFICATION } \\
\text { OF REPORT } \\
\text { UNCLASSIFIED }\end{array}$ & $\begin{array}{l}\text { 18. SECURITY CLASSIFICATION } \\
\text { OF THIS PAGE } \\
\text { UNCLASSIFIED }\end{array}$ & $\begin{array}{l}\text { 19. SECURITY CLASSIFICATION } \\
\text { OF ABSTRACT }\end{array}$ & 20. LIMITATION OF ABSTRACT \\
\hline
\end{tabular}


Destroy this report when no longer needed. Do not return it to the originator. 